OPEN ACCESS

Edited by:

Svetlana N. Dedysh,

Winogradsky Institute

of Microbiology (RAS), Russia

Reviewed by:

Marina G. Kalyuzhanaya,

San Diego State University,

United States

Steffen Kolb,

Leibniz-Zentrum für

Agrarlandschaftsforschung (ZALF),

Germany

*Correspondence:

Sung-Keun Rhee

rhees@chungbuk.ac.kr

tThese authors are joint first authors

Specialty section:

This article was submitted to

Terrestrial Microbiology,

a section of the journal

Frontiers in Microbiology

Received: 14 May 2018 Accepted: 06 August 2018 Published: 27 August 2018

Citation:

Nguyen N-L, Yu W-J, Gwak J-H, Kim S-J, Park S-J, Herbold CW, Kim J-G, Jung $M-Y$ and Rhee $S-K$ (2018) Genomic Insights Into the Acid Adaptation of Novel Methanotrophs Enriched From Acidic Forest Soils.

Front. Microbiol. 9:1982. doi: 10.3389/fmicb.2018.01982

\section{Genomic Insights Into the Acid Adaptation of Novel Methanotrophs Enriched From Acidic Forest Soils}

\author{
Ngoc-Loi Nguyen'1, Woon-Jong Yu'1t, Joo-Han Gwak', So-Jeong Kim², Soo-Je Park ${ }^{3}$, \\ Craig W. Herbold ${ }^{4}$, Jong-Geol Kim ${ }^{1}$, Man-Young Jung ${ }^{4}$ and Sung-Keun Rhee ${ }^{1 *}$
}

${ }^{1}$ Department of Microbiology, Chungbuk National University, Cheongju, South Korea, ${ }^{2}$ Geologic Environment Research Division, Korea Institute of Geoscience and Mineral Resources, Daejeon, South Korea, ${ }^{3}$ Department of Biology, Jeju National University, Jeju City, South Korea, ${ }^{4}$ Department of Microbiology and Ecosystem Science, Division of Microbial Ecology, University of Vienna, Vienna, Austria

Soil acidification is accelerated by anthropogenic and agricultural activities, which could significantly affect global methane cycles. However, detailed knowledge of the genomic properties of methanotrophs adapted to acidic soils remains scarce. Using metagenomic approaches, we analyzed methane-utilizing communities enriched from acidic forest soils with $\mathrm{pH} 3$ and 4 , and recovered near-complete genomes of proteobacterial methanotrophs. Novel methanotroph genomes designated KS32 and KS41, belonging to two representative clades of methanotrophs (Methylocystis of Alphaproteobacteria and Methylobacter of Gammaproteobacteria), were dominant. Comparative genomic analysis revealed diverse systems of membrane transporters for ensuring $\mathrm{pH}$ homeostasis and defense against toxic chemicals. Various potassium transporter systems, sodium/proton antiporters, and two copies of proton-translocating F1F0-type ATP synthase genes were identified, which might participate in the key $\mathrm{pH}$ homeostasis mechanisms in KS32. In addition, the V-type ATP synthase and urea assimilation genes might be used for $\mathrm{pH}$ homeostasis in KS41. Genes involved in the modification of membranes by incorporation of cyclopropane fatty acids and hopanoid lipids might be used for reducing proton influx into cells. The two methanotroph genomes possess genes for elaborate heavy metal efflux pumping systems, possibly owing to increased heavy metal toxicity in acidic conditions. Phylogenies of key genes involved in acid adaptation, methane oxidation, and antiviral defense in KS41 were incongruent with that of $16 \mathrm{~S}$ rRNA. Thus, the detailed analysis of the genome sequences provides new insights into the ecology of methanotrophs responding to soil acidification.

Keywords: methanotroph, acid adaptation, genome reconstruction, comparative genomics, Methylocystis, Methylobacter

\section{INTRODUCTION}

Soil methanotrophs play a significant role globally in the biogeochemical cycling of methane (Le Mer and Roger, 2001; Dutaur and Verchot, 2007) by oxidizing atmospheric methane and oxidizing subsurface methane before it can be released to the atmosphere (Semrau, 2011; Knief, 2015; Strong et al., 2015). Methanotrophs are group bacteria that utilize methane as 
their sole carbon and energy source (Söhngen, 1906; Hanson and Hanson, 1996; Raghoebarsing et al., 2006). Typical aerobic terrestrial methanotrophs belong to the classes Alphaproteobacteria (Type II) and Gammaproteobacteria (Type I). Methanotrophic bacteria belonging to the phylum Verrucomicrobia (Dunfield et al., 2007) and candidate phylum NC10 (Ettwig et al., 2010; He et al., 2016) have been reported from acidic thermal environments and anoxic environments, respectively. The key step in aerobic methane oxidation to methanol is catalyzed by the methane monooxygenase which occurs as a particulate, membrane bound form (pMMO) and as a soluble, cytosolic form (sMMO).

Soil acidification is accelerated by anthropogenic and agricultural activities, and naturally acidic soils $(\mathrm{pH} \leq 5)$ comprise about $30 \%$ of soils in the world (Behera and Shukla, 2015; Yu et al., 2015; Goulding, 2016). Upland forest soils have had less attention in terms of methane production and emission studies although those cover larger areas than wetlands (Megonigal and Guenther, 2008; Mukhin and Voronin, 2011). The upland forest soils harbor populations of methanogens. Thus, the upland forest soils can become net sources of methane especially when water content increases (Megonigal and Guenther, 2008; Hofmann et al., 2016). Since $\mathrm{pH}$ values of pine-dominated forest soils typically range between 3 and 4 (Lau et al., 2007; Megonigal and Guenther, 2008; Machacova et al., 2016), which is below the pH optimum of many cultured methanotrophs (Hanson and Hanson, 1996), acid adaptation of methanotrophs needs to be adequately characterized to evaluate methane oxidation in upland forest ecosystems.

Methanotrophic communities can be influenced by $\mathrm{pH}$ through (1) the effect of $\mathrm{pH}$ on any associated microbial communities and (2) by changing the availability of toxic elements and nutrients (Kizilova et al., 2013; Zhou et al., 2017). Methane oxidation activity in natural forest soils was shown to be suppressed under acidic conditions or was tolerant to this effect (Amaral et al., 1998; Saari et al., 2004). However, detailed genomic knowledge concerning the response of methanotrophs to acidification of soil remains scarce (Aronson et al., 2013).

Recent studies have identified diverse methanotrophs including novel uncultured clades in acidic environments (Kip et al., 2011; Arai et al., 2014; Baesman et al., 2015). Acidophilic methanotrophs of the alphaproteobacterial families Methylocystaceae and Beijerinckiaceae are common inhabitants of acidic environments (Dedysh, 2011). Two moderately acidophilic methanotrophs, Methylocystis heyeri and Methylocystis bryophila, in the family Methylocystaceae were isolated from acidic Sphagnum peat and have an optimal growth at $\mathrm{pH} 5.8$ and 6.5, respectively (Dedysh et al., 2007; Belova et al., 2013). Methanotrophs from three genera (Methylocella, Methyloferula, and Methylocapsa), belonging to the family Beijerinckiaceae, have been isolated from acidic habitats such as Sphagnum peat bogs and acidic forest soils. Members of these genera have a growth optimum at pH 4.8-5.5 (Dedysh et al., 2000, 2002, 2004; Vorobev et al., 2011). Acidophilic methanotrophs from the gammaproteobacterial family Methylococcaceae have also been isolated from various acidic environment. These include the acidophilic Methylomonas sp. M5 and Methylovulum sp.
M200 (Kip et al., 2011); acid-tolerant species Methylomonas paludis and Methylovulum psychrotolerans, with the ability to grow at $\mathrm{pH}$ as low as 4.0 (Danilova et al., 2013; Oshkin et al., 2016); and thermophilic strains Methylocaldum sp. BFH1 and BFH2 with optimal pH 5.5-6.0, respectively (Islam et al., 2016). Although members of Methylobacter have been detected in acidic forest soils, Sphagnum peatlands, and acidic enrichment cultures (Kolb et al., 2005; Kip et al., 2011; Baesman et al., 2015), no taxonomically characterized isolate belonging to the Methylobacter has shown capacity to grow at a $\mathrm{pH}$ below 5.0, including the recently descried taxa Methylobacter tundripaludum (Bowman et al., 1993; Wartiainen et al., 2006).

Comparative genomic analysis provides insights into metabolic pathways and eco-physiological properties (Kelly et al., 2005; Dam et al., 2013; Tamas et al., 2014; Vorobev et al., 2014). A previous genomic study of an extremely acidophilic verrucomicrobial methanotroph identified several candidate genes that may be important for its acidophilic lifestyle (Hou et al., 2008). However, only a limited number of genome sequences of acidophilic and acid-tolerant methanotrophs are available, particularly for Type I gammaproteobacterial methanotrophs. Studies on the comparative genomics of acidophilic proteobacteria are rare, further limiting our understanding of the physiological and biochemical mechanisms which support methanotrophic life under acidic conditions.

Here, we characterized methanotroph communities enriched from acidic forest soils using sequencing batch reactors (SBRs) at $\mathrm{pH} 3$ and 4. Using a metagenomic approach, we reconstructed genomes for two dominant methanotrophs belonging to the genera Methylocystis and Methylobacter. This study will help to expand our knowledge of the physiology and ecology of methanotrophs in acidic soils.

\section{MATERIALS AND METHODS}

\section{Enrichment of Methanotrophs From Acidic Soils}

Forest soil samples were collected from Korean pine (Pinus koraiensis)-dominated forests, but also having other tree species such as Quercus mongolica and Abies holophylla at Chungbuk National University and Gutdae Mountain sites at Cheongju, South Korea. The forest soil samples were consisted of the upper layers of organic matter $(0-5 \mathrm{~cm}, \mathrm{pH} 4.5-5.3)$ and the lower layers of mineral material mixed with organic matter (5$10 \mathrm{~cm}, \mathrm{pH} 4.0$ ). The soil samples from lower layer were collected and transported to the laboratory and used for inoculation. The locations and general properties of two soils are presented in Supplementary Table S1. The soils were frozen at $-80^{\circ} \mathrm{C}$ before extraction of DNA using the soil prep kit (GeneAll, Korea). Quantification of bacterial 16S RNA gene, pmoA, and $m m o X$ copy numbers in the soils was carried out using CFX Connect ${ }^{\mathrm{TM}}$ Real-Time System (Bio-Rad Laboratories, Hercules, CA, United States) and built in CFX manager software (version 3.0, Bio-Rad Laboratories, Hercules, CA, United States). The DNA in the range of 10-20 ng was used for quantification 
of target gene copies with the following primers: $518 \mathrm{~F} / 786 \mathrm{R}$ for 16S rRNA gene (Muyzer et al., 1993), A189F/mb661R for pmoA (Kolb et al., 2003), and 536F/898R for mmoX (Fuse et al., 1998). Standard curves generated for each run by using reference gene standards with gene copies ranging from 0 to $10^{9}$ per reaction were used to estimate gene copy numbers in samples.

Two methanotrophic communities, designated as R4 and R3, were enriched from a mixture of the two soils in SBRs at $\mathrm{pH}$ 4 and 3, respectively, to increase diversity of methanotrophs by retaining slow-growing methanotrophs. The volume of each reactor was $5 \mathrm{~L}$, consisting of $3 \mathrm{~L}$ of medium and $2 \mathrm{~L}$ of headspace with methane $(20 \% \mathrm{v} / \mathrm{v}$ in headspace). Two reactors were fitted with a fermenter lid containing a stirrer, a dissolved oxygen probe, a $\mathrm{pH}$ probe, acid and base in-flow tubes for $\mathrm{pH}$ control, temperature detector, gas line, feed in-flow tube, sampling line, and effluent-withdraw line. The low-salt mineral (LSM) medium (0.4 mM MgSO $4 \cdot 2 \mathrm{H}_{2} \mathrm{O}, 0.1 \mathrm{mM} \mathrm{CaCl} 2 \cdot 2 \mathrm{H}_{2} \mathrm{O}$, $0.2 \mathrm{mM} \mathrm{K}_{2} \mathrm{SO}_{4}$, and $1 \mathrm{mM} \mathrm{KH_{2 }} \mathrm{PO}_{4}$ ) was supplemented with final concentrations of $1 \mathrm{~mL} / \mathrm{L}$ trace element solution, $100 \mu \mathrm{L} / \mathrm{L}$ vitamin solution (Widdel and Bak, 1992), and $0.2 \mu \mathrm{M}$ cerium chloride. $\mathrm{NH}_{4} \mathrm{Cl}(0.1 \mathrm{mM})$ was supplied as a nitrogen source. $\mathrm{pH}$ was adjusted to $\mathrm{pH} 4$ and 3 with $0.2 \mathrm{~N} \mathrm{H}_{2} \mathrm{SO}_{4}$, for enrichments of R4 and R3, respectively. Each reactor was inoculated with soil (200 g/L each) and was operated at $30 \pm 1{ }^{\circ} \mathrm{C}$, with stirring at $500 \mathrm{rpm}$. The reactors were operated as SBRs with a cycle of 2 weeks, comprised of three phases: (i) settling period for $12 \mathrm{~h}$, (ii) withdrawal period for $0.5 \mathrm{~h}$, during which $75 \%$ of the effluent was replaced with an equal volume of fresh LSM, and the methane/air was replaced at the same ratio of $1: 4$ in the headspace, (iii) and reaction period in which biomass was incubated for about 13.5 days with continuous stirring. Reactor performance was checked using subsamples of the SBR biomass. In brief, $25 \mathrm{~mL}$ sub-cultures were taken from the SBRs and incubated in $150 \mathrm{~mL}$-serum vials with methane $(20 \% \mathrm{v} / \mathrm{v})$ in headspace in a shaking incubator. From the headspace, gas samples $(100 \mu \mathrm{L})$ were taken and methane consumption was measured using gas chromatography GC-2010 Plus (SHIMADZU, Japan). A GC/FID was equipped with a Rtx-1 GC column (film thickness, $0.25 \mu \mathrm{m}$; inside diameter, $0.25 \mathrm{~mm}$; length, $30 \mathrm{~m}$; Restek, Bellefonte, PA, United States) and a flame ionization detector. Nitrogen gas was used as a carrier, with a column flow rate of $1 \mathrm{~mL} / \mathrm{min}$. The chromatographic conditions: injector temperature, $150^{\circ} \mathrm{C}$ (split ratio of $1: 10$ ); oven temperature of $80^{\circ} \mathrm{C}$ held for detection time; detector temperature, $200^{\circ} \mathrm{C}$.

After 3 months, biomass was harvested from $1 \mathrm{~L}$ of culture by centrifugation at $10,000 \times g$ for $10 \mathrm{~min}$. The pellet was placed in a sterile conical tube and stored at $-80^{\circ} \mathrm{C}$ until further processing for community analysis based on PCR amplification of $16 \mathrm{~S}$ rRNA gene. For differential coverage-based binning of the methanotroph genomes from the metagenomes of the enrichment cultures, $1 \%$ of the culture from SBR was transferred to a $2 \mathrm{~L}$ bottle containing $1 \mathrm{~L}$ of a fresh LSM and $1 \mathrm{~L}$ of headspace with methane $\left(10 \% \mathrm{v} / \mathrm{v}\right.$ headspace) and incubated at $25^{\circ} \mathrm{C}$. After depletion of methane, the biomass was harvested for extraction of metagenomic DNA for sequencing.

\section{Whole DNA Extraction and Sequencing}

Total DNA was extracted from each pellet using a modified CTAB bead-beating method (Griffiths et al., 2000) to obtain metagenomic DNA extracts (R3 and R4). Briefly, biomass was ground with quartz and liquid nitrogen and treated with DNA extraction buffer at $65^{\circ} \mathrm{C}$ for $15 \mathrm{~min}$, and the nucleic acids were purified with chloroform/isoamyl alcohol. Metagenomic DNA integrity was confirmed using $0.8 \%(\mathrm{w} / \mathrm{v})$ agarose gel electrophoresis and DNA was quantified using a NanoDrop ND1000 spectrophotometer (Thermo Fisher Scientific, Waltham, MA, United States).

For community analysis, the V4 and V5 region of the $16 \mathrm{~S}$ rRNA gene were amplified using primers 515F (5'-GTG YCA GCM GCC GCG GTA A-3') and 926R (5' -CCG YCA ATT YMT TTR AGT TT-3') (Osburn et al., 2011), with sample indexing adapters (Nextera XT index kit). PCR amplifications were conducted via the following steps: 5 min heating step at $95^{\circ} \mathrm{C}$, followed by 25 cycles at $95^{\circ} \mathrm{C}$ for $45 \mathrm{~s}$ (denaturation), $50^{\circ} \mathrm{C}$ for $45 \mathrm{~s}$ (annealing), $68^{\circ} \mathrm{C}$ for $90 \mathrm{~s}$ (extension), and a final extension at $72^{\circ} \mathrm{C}$ for $5 \mathrm{~min}$. Sequencing of $300 \mathrm{bp}$ paired-end reads on the Illumina MiSeq platform was performed by Macrogen Inc., South Korea. The two metagenomic DNA extracts from the cultures derived from R3 and R4 were sequenced on the Illumina Hiseq 2000 (Illumina, San Diego, CA, United States) and Pacbio RSII platforms (Pacific Biosciences, Menlo Park, CA, United States) by Macrogen Inc., South Korea.

\section{S rRNA Gene Amplicon Analyses}

Reads were examined using FastQC v0.11.3, quality trimming and adapter removal were carried out with Trimmomatic v0.36 with default settings. Qualified paired-end reads were merged using the commercial software Geneious (version 9.1.8). For classification, merged reads were analyzed from SILVAngs web server (v. 1.7.01) (Andreas et al., 2014). The diversity and species richness indices were calculated by alpha_diversity.py script in Qiime (Caporaso et al., 2010) with rarified counts.

\section{Metagenome Assembly and Annotation}

Illumina data were quality trimmed with Sickle software (Joshi and Fass, 2011) and pooled with Pac-Bio reads, followed by hybrid-assembly using SPAdes v3.5.0 (Bankevich et al., 2012). Coding sequences (CDSs) in the assembled data were predicted using Prodigal in metagenomic mode (Hyatt et al., 2010). rRNAs and tRNAs were identified using RNAmmer (Lagesen et al., 2007) and tRNAscan-SE (Lowe and Chan, 2016), respectively. Functional predictions of the protein sequences were performed using BLASTp similarity searches based on the best BLAST hit against NCBI NR database (best bit score, cut off: query shared $>80 \%$ similarity, $>80 \%$ alignment coverage, and $e$-value $1 e^{-5}$ ) and KEGG (GhostKOALA) (Kanehisa et al., 2017). Clusters of orthologous groups (COGs) (Tatusov et al., 2001) and TIGRfam (Haft et al., 2001) were assigned to predicted genes with rps-blast $\left(e\right.$-value $\left.1 e^{-5}\right)$. Domain information was obtained using the Pfam database.

\footnotetext{
${ }^{1}$ https://www.arb-silva.de/ngs
} 


\section{Genome Reconstruction and Comparative Genomics}

Genomes of dominant microorganisms were reconstructed using differential coverage and tetranucleotide frequency as previously described (Albertsen et al., 2013). Trimmed HiSeq reads were mapped to the combined assembly with Bowtie2 (Langmead and Salzberg, 2012) and SAMtools (Li et al., 2009) to calculate coverage. CheckM v1.0.9 software was used to evaluate genomes (Parks et al., 2015) using criteria (completeness and contamination) to choose final bins for further analysis. Furthermore, all selected scaffolds were manually curated by taxonomic assignment of genes based on BLASTp results against the NR database (phylum level of hit gene to NR database; see above). Read depth of each scaffold, containing rRNA and pmo/pxm operons, was visualized using the R/Bioconductor package "Sushi" (Phanstiel et al., 2014). To check physical linkage of $p m o C A B$ of KS41, PCR amplification of pmoCAB of KS41 in metagenomics DNA was conducted using following primers: K1-F (5'-CAGTGAAAGCTGATGCTGCG-3') of pmoC, K2-R (5'-CGCTTCTGCACGAGACCTAA-3 $\left.{ }^{\prime}\right)$ of $p m o A$, and K3-R (5'-ATCAGCAGTGCGACAAAGGA-3') of pmoB. K1$\mathrm{F}$ and $\mathrm{K} 2-\mathrm{R}$ pair and $\mathrm{K} 1-\mathrm{F}$ and $\mathrm{K} 3-\mathrm{R}$ pair were used for $p m o C A(900 \mathrm{bp})$ and $p m o C A B$ (1760 bp) amplification, respectively.

Genome bins were compared to reference genomes by calculating Orthologous Average Nucleotide Identity (OrthoANI) values and constructing phylogenomic trees with the Orthologous Average Identity Tool (Lee et al., 2015). Genome wide comparison and annotation of orthologous genes across multiple species were performed using OrthoVenn (Wang et al., 2015). The orthologous clusters were identified with default parameters, $1 e^{-5} e$-value cutoff for all protein similarity comparisons, and 1.5 inflation value for the generation of orthologous clusters. Clustered Regularly Interspaced Short Palindromic Repeats (CRISPRs) and specific families of tandem repeats were detected by the CRISPRFinder tool (Grissa et al., 2007).

\section{Phylogenetic Reconstructions}

Single genes (16S rRNA gene and $p m o A$ encoding for a subunit of the pMMO) were aligned using ClustalX (Thompson et al., 1997) and manually edited in BioEdit (Hall, 1999). Phylogenetic trees were constructed in MEGA7 (Kumar et al., 2016) using the Neighbor-Joining method (Saitou and Nei, 1987) on distances calculated with a Kimura 2-parameter model. Pairwise identity of $16 \mathrm{~S}$ rRNA genes was determined with the Ezbiocloud server (Yoon et al., 2017). Phylogenetic analyses were also carried out for a set of 15 syntenic ribosomal proteins (Sorek et al., 2007; Castelle et al., 2015), pMMO proteins (PmoCAB), urea transporter proteins (UrtABCDF), and potassium transporter proteins (KdpFABCD). Derived protein sequences were aligned using ClustalX (Thompson et al., 1997) and sequence alignment data were joined using an online FASTA sequence toolbox, FaBox v. 1.41 (Villesen, 2007). Phylogenetic trees were constructed using the maximum-likelihood method under the best-fit model considering the relative rates of amino acid replacement in
MEGA7. Bipartition confidence for all trees was assessed with 1000 bootstraps (Felsenstein, 1985).

\section{RESULTS AND DISCUSSION}

\section{Soil Properties and Enrichment Cultures}

Soils used for obtaining enrichment cultures were acidic and typical for forest soils vegetated mostly by Korean pine (P. koraiensis L.). General properties are described in Supplementary Table S1. Methanotrophic communities were successfully enriched in SBRs at $\mathrm{pH} 4$ and 3, which were designated R4 and R3, respectively. After biweekly refreshment of medium and headspace for 3 months, methane consumption was verified using $25 \mathrm{~mL}$ enrichment subsamples which consumed $0.5 \mathrm{mmol}$ methane in 2 weeks (Supplementary Figure S1) with higher activities in the enrichments at $\mathrm{pH} 4$ than at $\mathrm{pH} 3$. The enrichment cultures obtained at the two different low $\mathrm{pH}$ values were used for comparison of the respective methanotroph communities.

\section{Methanotrophic Communities}

The diversity and community structure of methanotrophic enrichment cultures were assessed based on 16S rRNA gene amplicons and are summarized in Supplementary Table S2 and Figure 1. In Figure 1A, BLAST-based comparison of the $16 S$ rRNA gene sequence reads with the entries in the SILVA database indicated that members of the family Methylocystaceae (15.3\%), the family Xanthomonadaceae (14.6\%), and the family Acidobacteriaceae (8.7\%) were the most abundant microbial groups in R4. In contrast, the most abundant groups of sequences retrieved from R3 were affiliated with Acidobacteriaceae (14.7\%), Chitinophagaceae (12.2\%), an unknown family of Acidimicrobiales (10.5\%), Holophagaceae (10.3\%), Methylocystaceae (8.1\%), and Porphyromonadaceae (7.3\%). In terms of methanotrophy (shown in Figure 1B), members of the families Methylocystaceae and Methylococcaceae were abundant in both enrichments while members of the family Beijerinckiaceae were rare $(<0.1 \%)$. The higher relative abundance of the family Methylocystaceae than that of Methylococcaceae in both enrichment cultures (Figure 1B) is consistent with the results of previous in situ or microcosm studies (Lau et al., 2007; Kip et al., 2011; Sharp et al., 2014; Esson et al., 2016). The families Methylocystaceae, Methylococcaceae, and Beijerinckiaceae were represented by the members of the genera Methylocystis, Methylobacter, and Methylocapsa, respectively (Figure 1B). Alphaproteobacterial type II methanotrophs, including Methylocystis and Methylocapsa, have been detected in various acidic ecosystems and several have been isolated (Dedysh et al., 2002, 2007; Belova et al., 2013). Diverse Methylobacter species have also been detected in various acidic environments (Kolb et al., 2005; Kip et al., 2011).

Considering the relative abundance of methanotrophs in the original soils based on quantitative PCR of pmoA (Supplementary Table S1), methanotroph populations were enriched about 10-folds during laboratory incubations. The low relative abundance of methanotrophs (20.5 and 10.5\%) in 


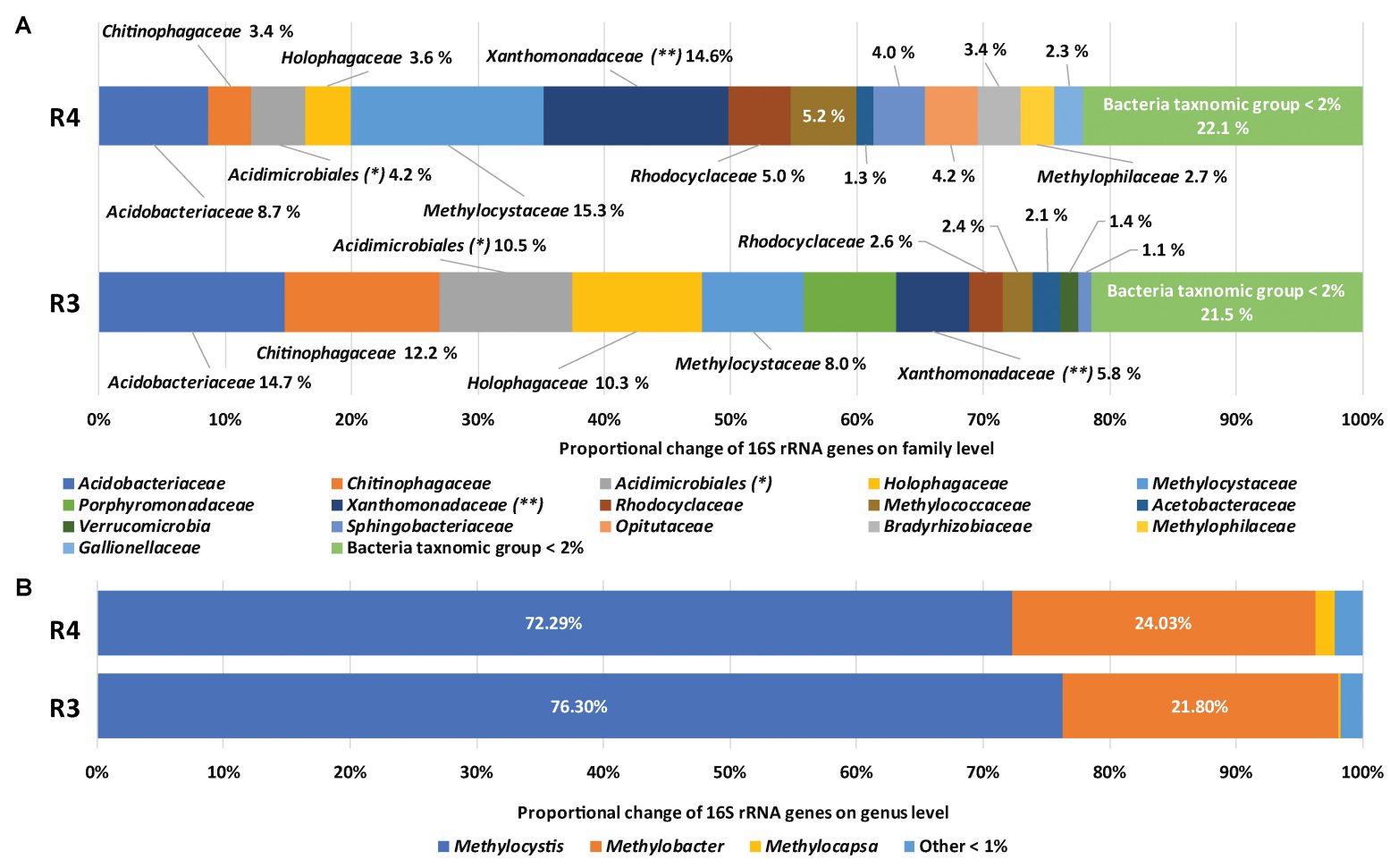

FIGURE 1 | Taxonomic assignments of 16S rRNA gene sequences of methanotrophic enrichment cultures. Relative compositions of microbial communities (A) and methane-oxidizing bacteria (B) in R4 and R3, respectively. * indicates unknown family of Acidimicrobiales, ** indicates Xanthomonadaceae and unknown family of Xanthomonadale.

the enrichment cultures, compared with that under neutral $\mathrm{pH}$ conditions (Kim et al., 2018), might be caused by slow growth of methanotrophs in acidic conditions (Supplementary Figure S1) and using SBR for enrichment method for retaining most of the settle-able biomass. The slow growth of methanotrophs in acidic conditions could be further indicated by the lower abundance of methanotrophs at $\mathrm{pH} 3(10.5 \%)$ than that $\mathrm{pH} 4$ (20.5\%). However, the relative abundance of individual genera (as a proportion of methanotrophs) did not significantly differ between treatments. Non-methanotrophs were more abundant at $\mathrm{pH} 3$ than at $\mathrm{pH} 4$ while the compositions were not significantly different from each other. Several studies have suggested association mechanisms between methanotrophs and non-methanotrophs, such as cross-feeding intermediates of methane metabolisms to non-methanotrophs (Oshkin et al., 2015; Krause et al., 2017) and supplying growth factors (e.g., cobalamin, vitamin $\mathrm{B}_{12}$ ) for methane oxidation from non-methanotrophs (Iguchi et al., 2011).

\section{Genome Reconstruction}

To gain genomic insight into acid adaptation of methanotrophs, genomes were reconstructed from metagenomic sequence reads (R4: 2.3 Gbp Illumina reads and 1.1 Gbp Pacbio reads, R3: 2.7 Gbp Illumina reads and 0.9 Gbp Pacbio reads) and the metabolic and physiological properties of the encoded proteins related to acid adaptation were investigated. Assembled scaffolds from the two enrichment cultures were binned using coverage and tetranucleotide frequency (Supplementary Figure S2). Three methanotroph genomes and two genomes affiliated to Beijerinckiaceae were reconstructed and the features are summarized in Table 1. The completeness of the genomes ranged from partial to near complete $(69.83-99.37 \%)$ as estimated by using CheckM analysis (Parks et al., 2015). The genome belonging to the family Methylococcaceae was designated KS41. Genomes designated KS32 and KS42 were affiliated with the family Methylocystaceae and ANI between KS32 and KS42 was $>99 \%$ suggesting that both genomes represent identical or nearly identical organisms. Genomes of methanotrophs belonging to the family Beijerinckiaceae were not obtained. Although phylogenetic analysis of ribosomal protein genes indicated that the genomes KS37 and KS44 were affiliated with the family Beijerinckiaceae, no genes encoding either pMMO or sMMO were found. Genome bins affiliated with the following nonmethanotrophic clades were also retrieved: Phenylobacterium of Alphaproteobacteria, Rhodanobacter of Gammaproteobacteria, Granulicella of Acidobacteria, Frankia of Actinobacteria, and Mucilaginibacter and Cytophagales of Bacteroidetes. Therefore, KS32 of Methylocystaceae and KS41 of Methylococcaceae were the key methanotrophs in the enrichment cultures and further analyses focused exclusively on these two genomes.

\section{Genomic and Phylogenetic Properties}

Publicly available genomes of methanotrophs closely related to KS32 and KS41 were retrieved for comparative genomics 
TABLE 1 | Features of the five reconstructed genome bins obtained through analysis of metagenomic sequences derived from the enrichment cultures R4 and R3.

\begin{tabular}{|c|c|c|c|c|c|}
\hline Genomic bin & KS41 & KS32 & KS42 & KS37 & KS44 \\
\hline Bin size (Mb) & 4,74 & 3,36 & 2,81 & 2,79 & 3,09 \\
\hline Number of contigs & 4 & 7 & 42 & 27 & 206 \\
\hline Completeness (\%) & 99.37 & 94.36 & 90.28 & 92.89 & 69.83 \\
\hline Contamination & 2.23 & 0.00 & 0.00 & 1.41 & 13.17 \\
\hline Strain heterogeneity & 0.00 & 0.00 & 0.00 & 0.00 & 0.00 \\
\hline Average contig size (kb) & 1,185 & 479 & 66 & 103 & 15 \\
\hline Average GC (\%) & 46.80 & 61.27 & 61.18 & 62.25 & 67.59 \\
\hline Number of predicted CDSs & 4,226 & 3,104 & 2,598 & 2,752 & 1,101 \\
\hline Number of genes with assigned function & 2,824 & 2,184 & 1,716 & 1,792 & 564 \\
\hline Number of predicted CDSs (Pfam) & 3,314 & 2,500 & 2,057 & 2,284 & 771 \\
\hline Number of predicted CDS (COG) & 2,219 & 1,848 & 1,558 & 1,777 & 540 \\
\hline Number of genes with assigned hypothetical protein & 1,238 & 813 & 740 & 886 & 409 \\
\hline tRNA & 44 & 47 & 41 & 31 & 16 \\
\hline 16S_23S_5S rRNA & 3_3_3 & 2_2_2 & 2_2_2 & 0_0_1 & ND \\
\hline Phylogenetic affiliation & Methylobacter & Methylocystis & Methylocystis & Beijerinckiaceae & Beijerinckiaceae \\
\hline Metagenome & $\mathrm{R} 4$ & $\mathrm{R} 3$ & R4 & R3 & R3 \\
\hline
\end{tabular}

Completeness, contamination, and strain heterogeneity were assessed with CheckM.

(Supplementary Table S3). Genome sizes, G+C contents, and number of CDSs of KS32 and KS41 were similar to the reference genomes. The majority of CDSs from KS32 were most similar to homologs in Methylocystis spp. (Methylocystis parvus $\mathrm{OBBP}^{\mathrm{T}}$, Methylocystis sp. ATCC 49242, and Methylocystis rosea $\mathrm{SV}^{\mathrm{T}}{ }^{\mathrm{T}}$ : $53 \%$ of total CDSs). Likewise, the majority of CDSs from the KS41 genome were most similar to homologs in Methylobacter spp. (M. tundripaludum: 35.3\% of total CDSs; Methylobacter luteus IMV-B-3098, Methylobacter marinus $\mathrm{A}_{4} 5^{\mathrm{T}}$, and Methylobacter whittenburyi ACM-3310: 15.56\% of total CDSs).

Phylogenetic trees based on the 16S rRNA gene and pmoA gene (encoding the beta-subunit of pMMO) were constructed in order to infer the phylogenetic relationships of the KS32 and KS42 to their close relatives. Both KS32 and KS41 genome bins contained pmoCAB operons while genes encoding sMMO were absent. Additionally, KS41 also contained the genes for pxmABC, the homolog of the $p m o C A B$, encoding a copper-containing membrane monooxygenase of unknown function (Tavormina et al., 2011; Hamilton et al., 2015). Based on the 16S rRNA gene and PmoA phylogenetic trees (Supplementary Figure S3), KS32 was most closely related to members of Methylocystis spp. and formed a monophyletic group with $M$. heyeri $\mathrm{H} 2^{\mathrm{T}}$ and Sakb1 which were isolated from acidic soil environments. KS32 was most similar to $M$. heyeri $\mathrm{H}_{2}^{\mathrm{T}}$ (99.1\% $16 \mathrm{~S}$ rRNA identity), although genomes for $M$. heyeri are not currently available for further comparison. The $16 \mathrm{~S}$ rRNA gene similarities between KS32 and other type strains of the genus Methylocystis were high. These included strains $M$. bryophila $\mathrm{H}_{2} \mathrm{~s}^{\mathrm{T}}$ (97.9\%), M. rosea SV97 $^{\mathrm{T}}$ (97.7\%), M. hirsuta CSC1 ${ }^{\mathrm{T}}$ (97.6\%), M. parvus $\mathrm{OBBP}^{\mathrm{T}}$ (97.2\%), and M. echinoides IMET 10491 (97.2\%). However, the genomes of these type strains share low ANI (72.9-73.9\%) with KS32 and KS42 (Figure 2A). Thus, KS32 and KS42 are likely new members of $M$. heyeri.

The 16S rRNA gene sequence from KS41 shared 96.2$98.4 \%$ identity with those from members of the genus
Methylobacter, forming a strongly supported clade with M. tundripaludum SV96 ${ }^{\mathrm{T}}$, M. psychrophilus $\mathrm{Z}-0021^{\mathrm{T}}$, and the taxonomically uncharacterized Methylobacter sp. strain T20 (Supplementary Figure S4A). Phylogenetic trees based on 15 concatenated conserved ribosomal proteins (Figure 3) also matched well with the $16 \mathrm{~S}$ rRNA tree. The $p m o A$ gene sequence of KS41 was as similar to the gene sequences from Methylovulum (M. miyakonense HT12 ${ }^{\mathrm{T}}$, 88.6\%; Methylovulum sp. M200, 87.83\%; and M. psychrotolerans $\left.\mathrm{Sph}^{\mathrm{T}}, 88 \%\right)$ as it was to Methylobacter (Methylobacter sp. CMS7, 89.18\%; M. psychrophilus Z-0021 ${ }^{\mathrm{T}}, 87.5 \%$; and $M$. tundripaludum SV96 ${ }^{\mathrm{T}}, 86.78 \%$ ) and the PmoA phylogeny was poorly resolved (Supplementary Figure S4B). A lack of resolution and a phylogenetic tree based on the concatenated PmoCAB also places KS41 as a sister taxon to Methylovulum (Supplementary Figure S5) rather than the Methylobacter clade. The placement of KS41 in both the 16S rRNA gene and concatenated ribosomal protein phylogenies is not congruent with the single-gene $p m o A$ and the concatenated PmoCAB tree, due to the lack of resolution in the latter two phylogenies. Since metagenomic binning can result in misplaced scaffolds, we explored this as a possible explanation for the incongruency between the 16S rRNA gene and PmoCAB phylogenies. Correct assembly and binning were verified by examining coverage and the alignment of raw reads to scaffolds (Supplementary Figure S6). The uniform depth of coverages of the scaffolds of KS41 and KS32, including rRNA operons and pmo/pxm operons indicate that these genes were not misassembled or assigned to incorrect bins. Further, successful PCR amplification of pmoCA and pmoCAB of KS41 from metagenomic DNA indicates physical linkage of the genes by correct assembly.

The values of ANI between KS41 and three Methylobacter strains (77.0-73.5\%) or two Methylovulum strains (71.6$72.5 \%)$ indicate the closer genomic similarity between KS41 and Methylobacter than Methylovulum (Figure 2B). The ANI 
A

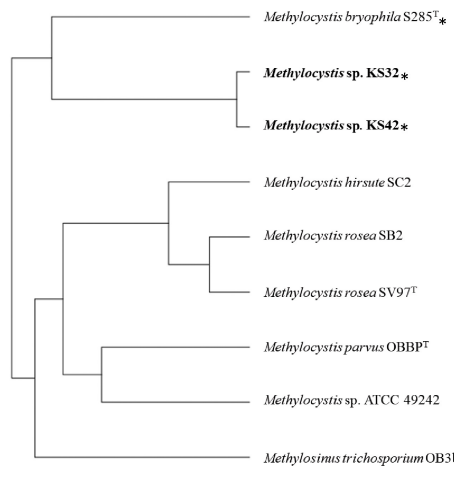

B

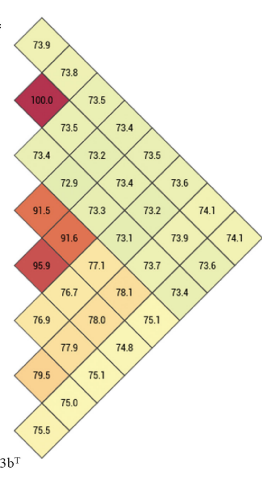

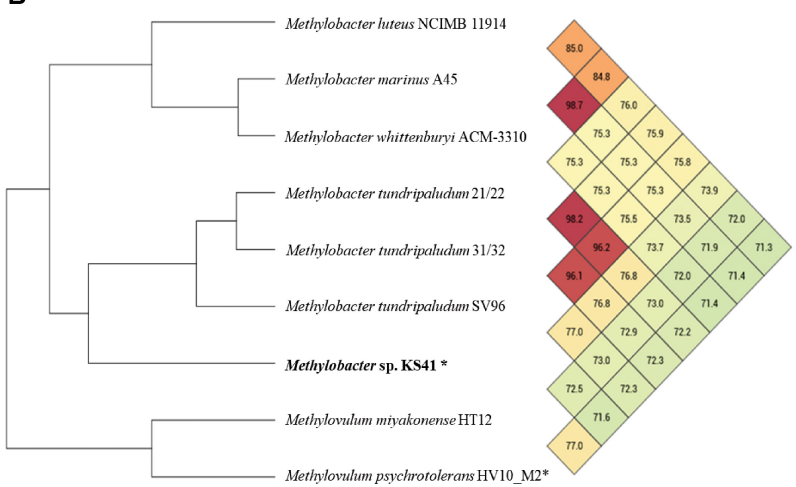

FIGURE 2 | Heatmap and phylogenomic tree based on average nucleotide identity (ANI) values calculated from Orthologous Average Nucleotide Identity Tool (OAT) software of the genome bins of KS42, KS32 (A), KS41 (B), and other reference species. Values larger than $95 \%$ indicate that strains belong to the same species. * indicates acid-tolerant/acidophilic strains.

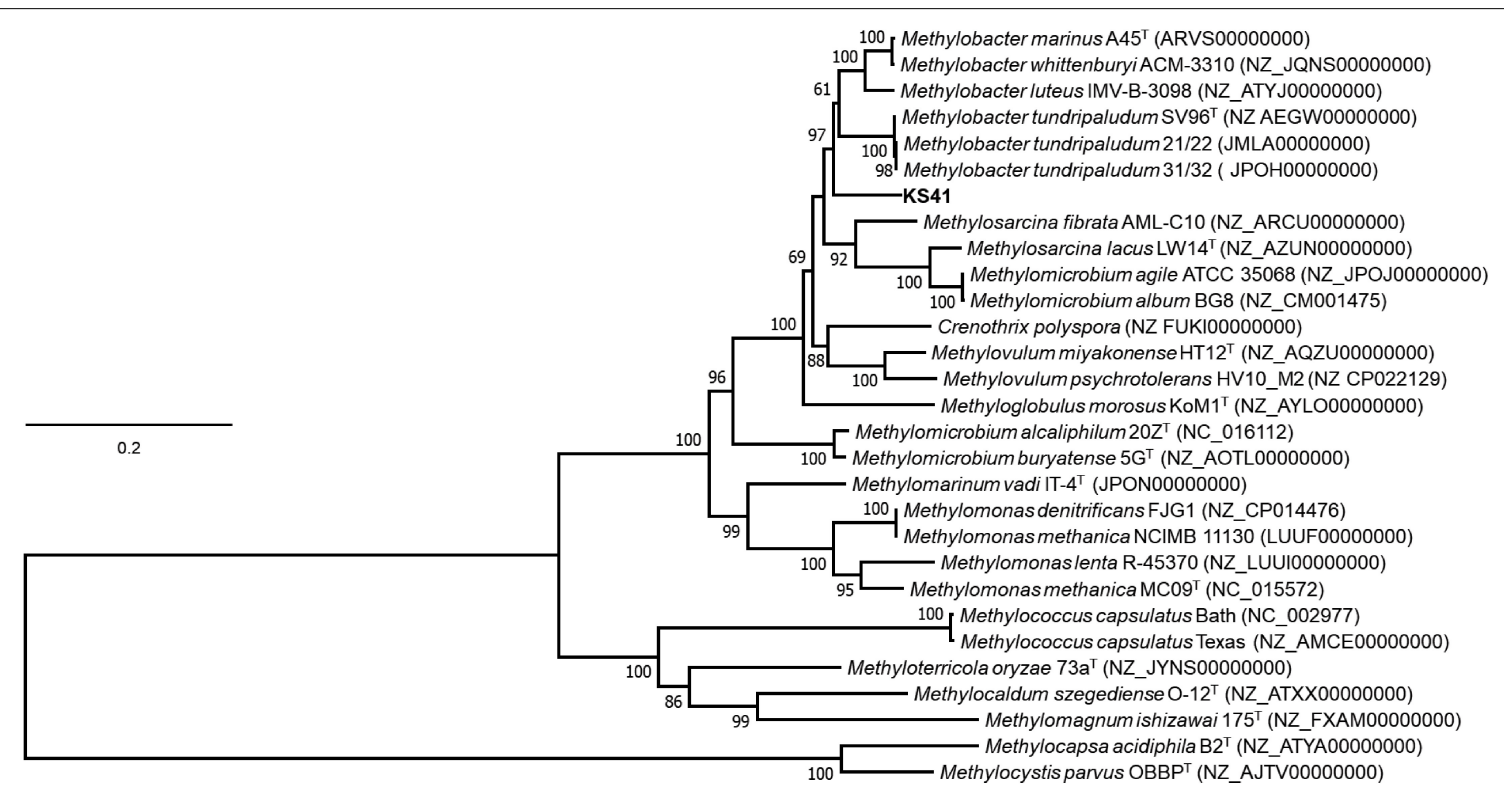

FIGURE 3 | Phylogenetic tree based on a concatenation of 15 syntenic ribosomal proteins of different members of type I methanotroph. The phylogenetic analysis was implemented using the maximum-likelihood method using the Le Gascuel model based on a concatenation of 2467 amino acids total length with 1000 bootstraps. Bootstrap values of $>60 \%$ from the maximum likelihood, respectively, as indicated at branch points. The scale bar represents 0.1 change per amino-acid position. Genome accession numbers are listed in parentheses. Two type-II methanotrophs, Methylocapsa acidiphila B2 ${ }^{\top}$ and Methylocystis parvus $\mathrm{OBBP}^{\top}$, were used as the outgroup. Evolutionary analyses were conducted in MEGA7.

threshold of 95-97\% was suggested for species circumscription (Tindall et al., 2010; Lee et al., 2015; Rossello-Mora and Amann, 2015; Thompson et al., 2015) and although KS41 and other Methylobacter species share over $97 \%$ identity on the level of $16 \mathrm{~S}$ rRNA gene, these organisms represent unique species according to ANI. Altogether, we propose the name " $\mathrm{Ca}$. Methylobacter pinensis KS41" for this species.

\section{Central Metabolism}

All genes required for a methanotrophic lifestyle and for the utilization of various nitrogen sources (Supplementary Table S4) were identified in KS41 and KS32 and most of these genes reside in the conserved syntenic regions. A single copy of the $p m o C A B$ operon is present in genome KS41 while two copies of the $p m o C A B$ operon are present in genome KS32. The genes involved in methanol oxidation (PQQ-dependent dehydrogenase) and formaldehyde oxidation (tetrahydromethanopterin-linked pathway) are present in both assembled genomes. Genomes KS41 and KS32 also encode genes to fix carbon via the ribulose monophosphate pathway and serine pathway, corresponding to type I and type II methanotrophy, respectively. Although the genes encoding for enzymes involved in the serine pathway were present in the KS41 genome, the genes encoding for the malyl-CoA/(S)-citramalyl-CoA 

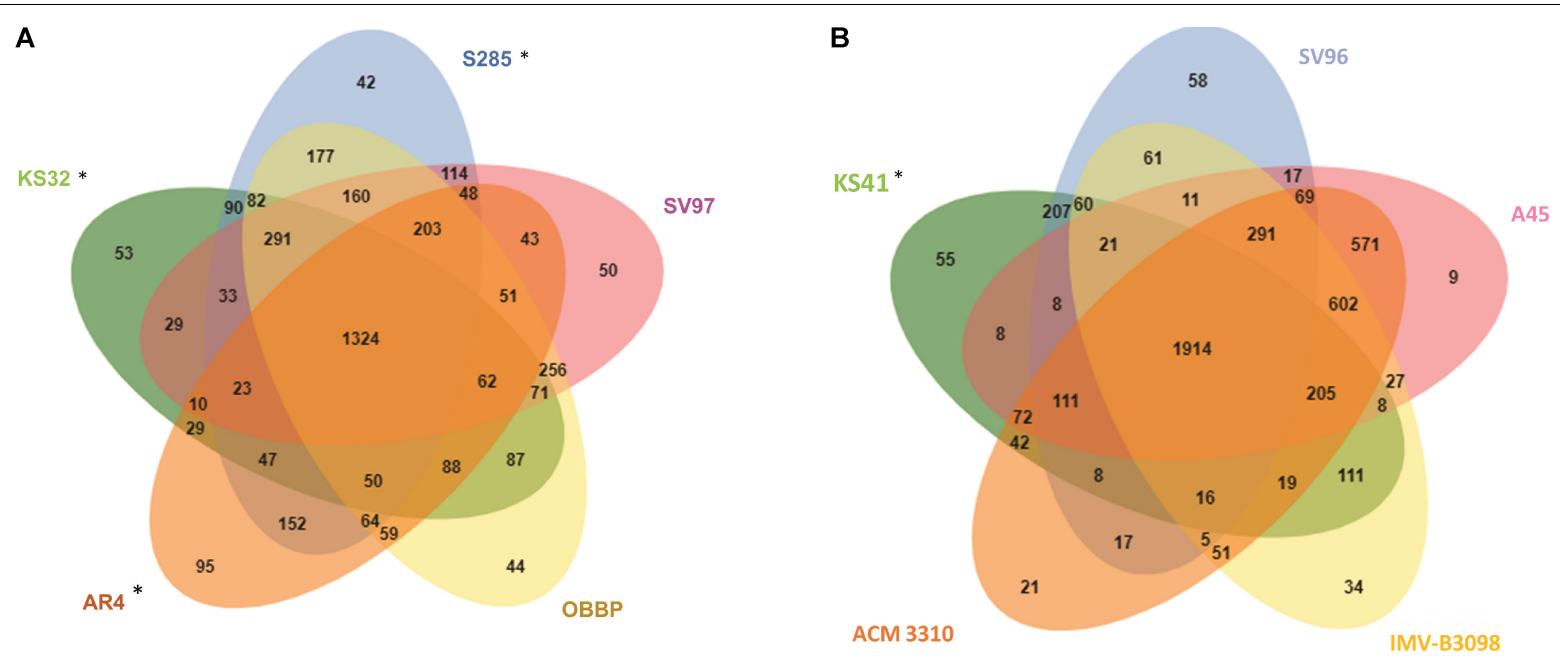

FIGURE 4 | Venn diagrams showing the numbers of shared proteins among Methylocystis and Methyloferula genus (A), Methylobacter genus (B). * indicates acid-tolerant/acidophilic strains.

lyase, hydroxypyruvate reductase, and phosphoenolpyruvate carboxylase could not be found. The incomplete serine pathway was reported in the genomes of Methylobacter (Supplementary Tables S3, S4) as well as Methylovulum (Hamilton et al., 2015). Genes involved in glycolysis, the pentose phosphate pathway, and the TCA cycle were also present in both KS41 and KS32.

Genes in each genome encoded for proteins with the potential for assimilation of nitrate and nitrite, hydroxylamine oxidation, nitrogen fixation, and denitrification. Proteins with the ability to transport nitrate/nitrite across the cytoplasmic membrane (NasA) and reduce it to ammonia (NirBD) may be encoded in both KS41 and KS32. Clusters of genes for urea transport and hydrolysis were identified only in KS41. pMMO can convert ammonia to hydroxylamine which is presumably detoxified by hydroxylamine reductase ( $h c p$ ) in KS32 (Wolfe et al., 2002; Cabello et al., 2004). In the case of KS41, a gene for flavohemoglobin $(h m p)$ might be involved in the detoxification of nitric oxide (Bonamore and Boffi, 2008; Vekeman et al., 2016).

\section{Comparative Analysis of COGs}

The Venn diagram calculated using OrthoVenn program shows the overlapping orthologous protein clusters between the genomes of KS41 and KS32 and closely related taxa (Figure 4). Comparative genome analysis between KS32 and other acidophilic/acid-tolerant strains of Methylocystis and Methyloferula revealed 3,927 intersecting COGs and 1,324 core COGs (Figure 4A). Among the three acidophilic methanotroph genomes, 47 COGs with 169 CDSs (58\% hypothetical proteins) were shared (Supplementary Table S5). GO-enrichment analysis of the 47 COGs identified several GO-ID including proton-translocating ATP synthase activity (GO:0046933, GO:0046961, GO:0045263, and GO:0042777 group 4 COGs including 12 CDSs) and drug transmembrane transport (GO:0006855 and GO:0015238 group 2 COGs including 7 CDSs) with $<0.05 P$-values, which may indicate mechanisms for growth under acidic conditions.

Comparisons of KS41 with those of neutrophilic Methylobacter species including $M$. tundripaludum $\mathrm{SV}^{\mathrm{T}}{ }^{\mathrm{T}}$, M. whittenburyi ACM-3310, M. luteus IMV-B-3098, and a halophilic strain, M. marinus $\mathrm{A} 45^{\mathrm{T}}$ identified 4,709 COGs with functional predictions within the four reference genomes of the genus Methylobacter and KS41 as shown in an OrthoVenndiagram (Figure 4B). This analysis predicted 1914 core COGs for all five genomes. KS41 genome shared 2,865 COGs with 3,076 CDSs with those of other Methylobacter genomes, sharing the highest number of COGs with a neutrophilic strain, M. tundripaludum SV96 ${ }^{\mathrm{T}}$ (207 COGs with 431 CDSs) (Supplementary Table S6). GO-enrichment analysis of KS41specific genes identified GO-IDs for cellular response to acidic pH (GO:0071468 with 1 COG containing two genes). GO analysis indicated that many genes for genomes KS41 and KS32 were involved in acid adaptation and the genes are shared with other acidophilic/acid-tolerant microorganisms.

\section{Features of Genomes That Support Acid Adaptation}

Complex effects of the proton concentration gradient across the membrane as well as an increased availability of toxic substrates such as heavy metal ions are stressful to microorganisms in acidic environments (Baker-Austin and Dopson, 2007). Comparative genomic analysis of the genomes recovered by us with those of related methanotrophs revealed potential mechanisms adopted by acidophilic methanotrophs for maintaining $\mathrm{pH}$ homeostasis and adaptation to various stresses in acidic environments. As summarized in Supplementary Table S7, KS32 and KS41 contained 232 genes involved in acid adaptation and shared 91 genes based on KEGG. However, blast analysis indicates that the genes of KS32 and KS41 had the highest similarity to different organisms indicating that no gene was closely 
related to each other. Most of the genes involved in acid adaptation in KS32 are not specific to acidophilic methanotrophs, while some of the genes involved in acid adaptation in KS41 are related to M. miyakonense $\mathrm{HT} 12^{\mathrm{T}}$, as indicated in Supplementary Table S4. This might be caused by a scarcity of genomic information on acidophilic methanotrophs. In fact, only one acidophilic Methylocystaceae genome (M. bryophila S285) genome and two acid-tolerant Methylococcaceae genomes (two genomes from Methylovulum) genomes are available in a public database.

\section{KS32}

Acid-resistance mechanisms of KS32 include using ion transporter systems for pumping potassium or other cations into cells and pumping protons out of the cell. An extensive array of potassium uptake systems such as a Kup-type low affinity potassium transporter, Trk-, Kch-, and Kef-type potassium transporters, and a Kdp-type high-affinity potassium transporter were found in KS32 (Supplementary Table S7). The potassium uptake-system has been shown to also transport ammonium ions which may effectively regulate cytoplasmic $\mathrm{pH}$ (Buurman et al., 1991). Genes encoding the high-affinity ATP-driven potassium transporter $(k d p F A B C)$ are located downstream of two osmo-sensitive signal transduction histidine kinases $(k d p D)$ and a response regulator $(O m p R)$. Proton exporters also play a primary role in regulating cytoplasmic $\mathrm{pH}$ (Baker-Austin and Dopson, 2007) and several homologs of a sodium/proton antiporter gene (nhaD) were found in KS32, which may function to export excess protons and simultaneously import sodium ions (Herz et al., 2003). Interestingly, KS32 carries two copies of the F1F0-type ATP synthase genes (Supplementary Table S4), which was observed in the genome of an acidophilic verrucomicrobial methanotroph, M. infernum (Hou et al., 2008). While one copy is most similar to that in Methylocystis, the other is most similar to those from non-methanotrophic Alphaproteobacteria. Since ATP synthase is reversible, it is tempting to suggest that the presence of two operons of ATP synthase genes might be associated with $\mathrm{pH}$ homeostasis. The genome of KS32 also encoded genes for a metabolic pathway for hopanoid synthesis (Supplementary Table S7) which may be important for adapting membranes for life in acidic environments (Jones et al., 2012). Many proteins are involved in the protection and repair of macromolecules damaged by acid stress. Molecular chaperons such as dnaK and groEL were found in genome KS32, which may prevent periplasmic-protein aggregation under acidic conditions (Merrell and Camilli, 2002; Tucker et al., 2002; Cotter and Hill, 2003).

\section{KS41}

KS41 contains more potassium uptake systems than KS32 (Supplementary Table S7) and encodes a gene for a putative chloride channel protein, EriC, of the CLC voltage-gated chloride channel family. EriC protein may remove $\mathrm{Cl}^{-}$(or other suitable anions) from the cell thereby preventing hyperpolarization (Foster, 2004). KS41 contains a gene cluster for urea assimilation including a urease and an ABC transporter for urea. Urea hydrolysis increases $\mathrm{pH}$ and thus can be used for acid resistance as suggested in Helicobacter pylori (Stingl et al., 2002; Scott et al., 2010). Unexpectedly, the phylogenetic analysis of urea transporter proteins (UrtABCDE proteins, Supplementary Figure S7A) and potassium transporter proteins (KdpFABCD, Supplementary Figure S7B) indicates that the genes are clustered to a clade containing acidophilic/acid tolerant Methylovulum species rather than those of Methylobacter species, similar to the results from the phylogenetic analysis of PmoCAB (Supplementary Figure S5). In the genomes of neutrophilic $M$. tundripaludum, neither genes for urea uptake nor urea hydrolysis were found. One potential explanation for this finding is that KS41 lost the genes for the urea transporter and acquired the genes from the clade harboring acidophilic Methylovulum.

KS41 harbors a cluster of genes encoding for bacterial V-type ATP synthase as well as that for F1F0-type ATP synthase (Supplementary Table S4). Such a V-type ATP synthase was not detected in the genome of $M$. tundripaludum strains. The V-type ATP synthase operon is the most similar to that of Planctomycetes (such as Planctomyces brasiliensis, Rhodopirellula maiorica), and, thus, is likely to have been acquired by a lateral gene transfer event, which could be supported by a phylogenetic tree of the transmembrane C/K subunits of KS41, another methanotroph, and Planctomycetes known specifically to be V- or F-type (Supplementary Figure S8A). V-type ATP synthases are widely observed in acidophiles which maintain pH homeostasis (Lolkema et al., 2003; Forgac, 2007) by coupling ATP hydrolysis with proton export. A hydrophobic amino acid $\left(\mathrm{A}_{560}\right)$ in the ATP/ADP-binding site may favor proton pumping activity and selectivity of proton/sodiumbinding sites of ATP synthase is largely set by the balance of flanking polar and hydrophobic groups (Murata et al., 2008; Schlegel et al., 2012; Leone et al., 2015). For KS41, key hydrophobic residues associated with the ATP/ADP-binding site (Supplementary Figure S8B) and the binding site of proton/sodium (Supplementary Figure S8C) suggest that the V-type ATPase functions as a proton pump. However, since conserved motifs of V-type ATP synthases are similar in neutrophilic, halophilic, and acidophilic methanotrophs, the roles of these V-type ATP synthase in $\mathrm{pH}$ homeostasis need to be verified in the future.

The genome of KS41-encoded genes to synthesize cyclopropane-fatty-acyl-phospholipids $(c f a)$ that protect the cell from proton influx under acidic conditions (Mangold et al., 2013b; Lund et al., 2014; Muhling et al., 2016). KS41 also contained genes for starvation-inducible outer membrane lipoprotein (Slp) which is often co-expressed with other acid resistance genes (Foster, 2004; Hou et al., 2008). Interestingly, two putative genes encoding homologs of a molecular chaperon, HdeA, which supports acid resistance in E. coli (Gajiwala and Burley, 2000) were also identified in KS41.

The phylogeny of genes providing several key mechanisms for adaptation to acidic environment, particularly those focused on modification of membrane lipids and transport proteins such as $\mathrm{KdpFABCD}$, UrtABCDE, and NtpC of bacterial V-type ATP synthase of KS41 is inconsistent with that of the 16S rRNA. 
A Predicted type I-E CRISPR/Cas system (in scaffold_1)

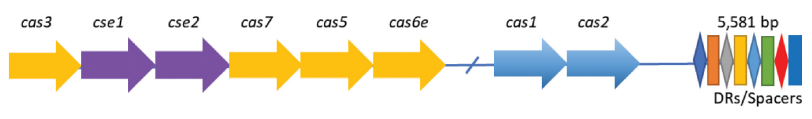

B Predicted type III-A CRISPR/Cas system (in scaffold_3)

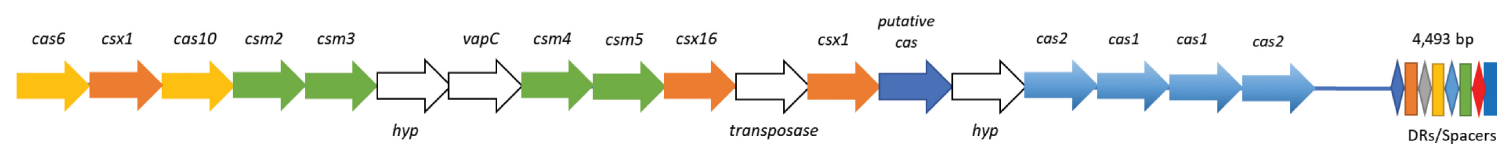

FIGURE 5 | Proposed CRISPR/Cas systems in KS41. KS41 contains (A) a putative subtype I-E and (B) a putative subtype III-A CRISPR/Cas system. The type I-E CRISPR/Cas system has genes encoding for Cas1/Cas2 and Cas3 proteins, and accessory proteins Cse1/Cse2, Cas7, Cas5, and Cas6e. The type III-A system has a cluster of genes for Cas6, Cas10, and repeat-associated mysterious proteins (RAMPs, Csm2-Cms6), a putative Cas protein. The system has genes coding for one transposase protein and two hypothetical proteins (hyp) with unknown functions.

\section{Heavy Metal Resistance and Response to Oxidative Stress}

Due to the increased solubility of various heavy metals at acidic pH (Johnson, 1998; Nordstrom and Alpers, 1999; Nordstrom et al., 2000), acidophilic methanotrophs must have defense mechanisms against heavy metal toxicity. Both KS32 and KS41 genomes encode elaborate systems for heavy metal efflux pumping systems which are frequently observed in other acidophilic microorganisms: Czc heavy metal efflux pump (resistance-nodulation-cell division transporters, RND) (BakerAustin et al., 2005), ZntA metal-transporting ATPase, AcrAB multi-drug efflux pump (Mangold et al., 2013a), and a major facilitator superfamily MFS/drug resistance MFS transporter (Supplementary Table S7). In addition, genes for copper resistance $(\operatorname{cop} C D)$ and tellurite resistance (ter $B)$, suggested to be involved in metal homeostasis (Dopson and Holmes, 2014), were identified. Genes for arsenate reductase (ars $C$ along with $\operatorname{ars} R C D A$ ) and mercuric reductase (mer $A$ ), which are involved in speciation of metals into less toxic forms (Dopson and Holmes, 2014), were linked to efflux pumps for arsenite $(\operatorname{ars} B)$ and mercury (merT mercuric transporter along with merRTPA), respectively. Additionally, Clp genes were found $(c l p B$ and $c l p X P)$ which may unfold and degrade aggregated proteins as an adaptation to acidic conditions (Mogk et al., 2003; Sugimoto et al., 2006). An acriflavin resistance protein $(\mathrm{AcrB})$ which is involved in protection from hydrophobic inhibitors (Singh et al., 2010) was found. KS32 contains an additional high-affinity ZnuABC to transport zinc. Cellular damage from high concentrations of toxic substances is frequently associated with the increased production of reactive oxygen species (Silver and Phung, 1996). Both genomes contain an extensive array of response genes for anti-oxidative stresses (Supplementary Table S7).

\section{CRISPR-Cas}

CRISPR-Cas systems are widespread across acidophilic archaea and bacteria and are involved in antiviral defense
(Rath et al., 2015; Quatrini et al., 2016). Interestingly, KS41 has 2 CRISPR loci with 154 spacers (Figure 5) as well as the corresponding Cas genes (Supplementary Table S8). Two different types of CRISPR-Cas systems were also detected in the genome of $M$. tundripaludum SV60 ${ }^{\mathrm{T}}$ (Supplementary Table S8). We could not detect any CRISPR-like sequence in the genome of KS32 or in the phylogenetically related acidophilic methanotrophs, Methylocystis and Methyloferula. According to the classification and nomenclature of CRISPR-associated genes, KS41 contains type I-E containing cas123 (Makarova et al., 2011) and type III-A containing cas12, cas6, cas10, and csm2345 (Makarova et al., 2011; Samai et al., 2015). The type I-E CRISPR-Cas system consists of Cas genes which are more closely related to those of acidophilic Methylovulum miyakonense strain than those of Methylobacter with a high conservation of gene organization and nucleotide identities in cas3 (94\%), cse1 (53\%), cse2 (62\%), and cas5 (94\%). The III-A CRISPR-Cas system contains additional $\operatorname{cs} x 1$ and $\operatorname{cs} x 16$ of the type III-U system and two copies of cas1/cas 2 which are observed in the genome of an acidophilic iron- and sulfur-oxidizing bacterium Acidithiobacillus ferrivorans strain YL15 (Peng et al., 2017). Type I-E and type III-A CRISPR-Cas systems have different viral targets: type I-E targeting viral DNA and type III-B targeting both viral DNA and RNA, respectively (Makarova et al., 2011). Thus, two different CRISPR Cas systems with a large number of spacers may increase resistance to viral infection, which indicates that viral predation may be a key ecological pressure for the survival of Methylobacter sp. in acidic conditions.

Vast areas of forest soils are experiencing acidification, and acidic wetlands and peat bogs are ecological hot spots because of climate change. Many ecological studies on acidophilic proteobacterial methanotrophs have been conducted in these environments (Lau et al., 2007; Kip et al., 2011; Baesman et al., 2015). So far, studies on adaptation of proteobacterial methanotrophs to acidic environments on genomic levels are rare. Comparative genomic analysis in this study enabled us to understand mechanisms involved in acid adaptation 


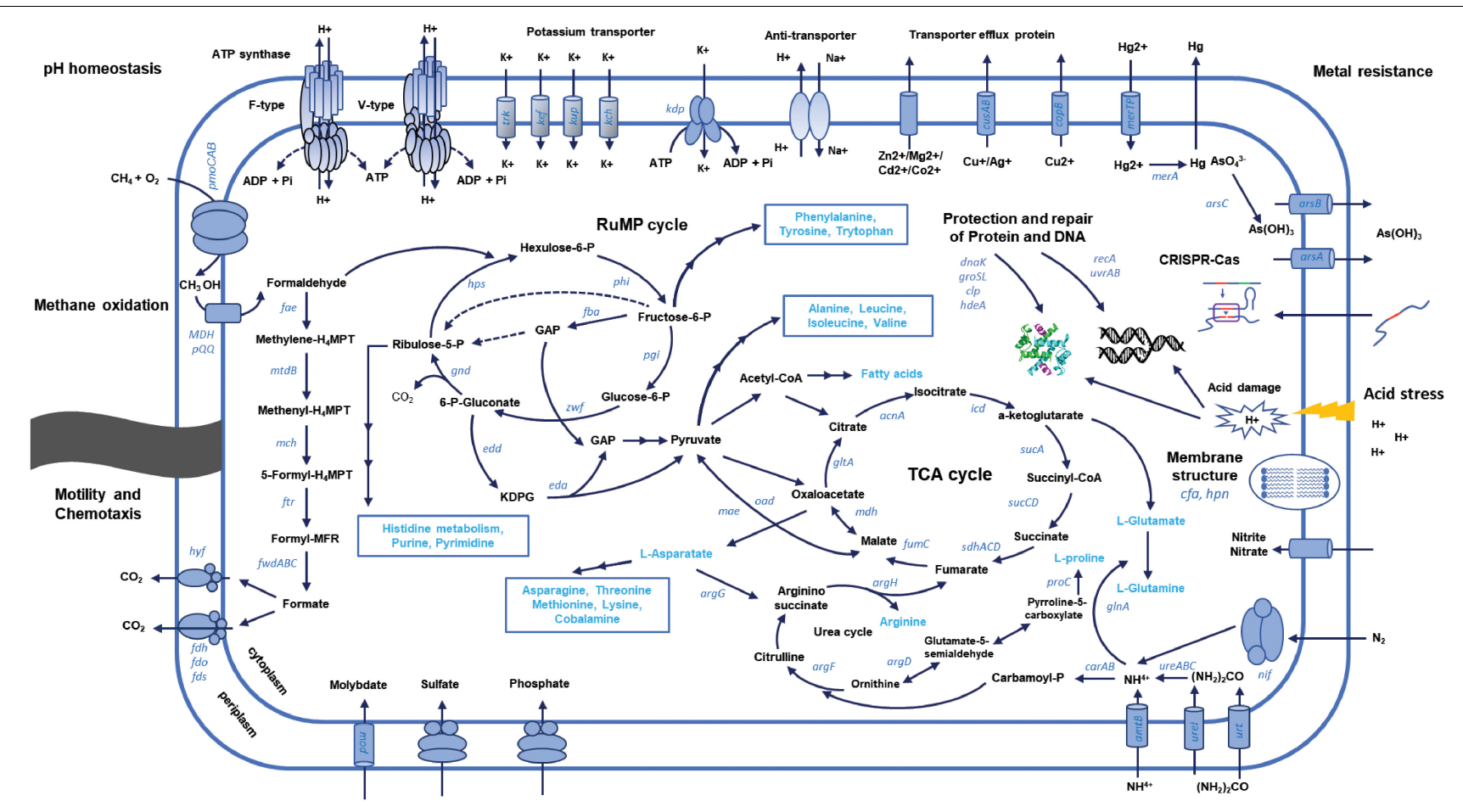

FIGURE 6 | Schematic representation of the metabolic pathways and processes involved in the adaptation of KS41 to acidic condition.

in proteobacterial methanotrophs. The genes involved in acid adaptation mechanisms are closely related to those of neutrophilic methanotrophs or acidophilic non-methanotrophic proteobacteria. Scarcity of genome information of acidophilic methanotrophs limits further investigation of mechanisms specific to acidophilic methanotrophs. KS41 is a rare model of gammaproteobacterial methanotrophs from acidic soils and distinct features for acid adaptation of KS41 could be revealed based on comparative genomics. A schematic model for selected gene products and processes involved in acid adaptation of novel gammaproteobacterial KS41 has been summarized in Figure 6 with those for K32 in Supplementary Figure S9. The genomic reconstruction-based comparative genomics used in this study is still challenging due to the potential problems with (1) contamination during assembly and binning and (2) incoherence between genotype and phenotype. Thus, mechanisms of acid adaptation of methanotrophs suggested in this study warrants further investigation.

\section{CONCLUSION}

This study identified mechanisms involved in acid adaptation of methanotrophs using comparative analysis of genomes obtained from pine forest soils. The two dominant genomes affiliated to Methylocystis (Alphaproteobacteria) and Methylobacter (Gammaproteobacteria) of type II and type I methanotrophs in SBR had several common features for acid adaptation: (1) Key mechanisms for acid resistance identified involved membrane transport proteins associated with cytoplasmic $\mathrm{pH}$ homeostasis and resistance to heavy metals. (2) Other mechanisms, including membrane modification and DNA and protein repair may be employed for adaptation to acid stress. In addition, distinct features were also observed in each genome: KS41 and KS32. The phylogenetic analysis indicated that phylogenies of some of the key genes involved in acid adaptation in KS41 were incongruent with that of $16 \mathrm{~S}$ rRNA gene. With the increasing numbers of acidophilic methanotroph genomes identified, the significance of the features identified in this study could be assessed. This should be followed by confirmation using pure cultures as well as natural acidic soils.

\section{DATA ACCESSIBILITY}

The metagenomic datasets have been deposited in the NCBI SRA database with BioProject number PRJNA470568 (SRR7135743 and SRR7135742). The assembled genomes of Methylocystis sp. KS32 and Methylobacter sp. KS41 are deposited at DDBJ/ENA/GenBank under the accessions PHSQ00000000 and PHSP00000000.

\section{AUTHOR CONTRIBUTIONS}

S-KR conceived this work. N-LN and W-JY performed the cultivation and DNA extraction. Genome analysis was carried out by J-HG, S-JK, S-JP, and CH. J-GK and M-YJ analyzed the 
sample properties. Manuscript was written by N-LN, S-KR, and $\mathrm{CH}$. All authors read and approved the final manuscript.

\section{FUNDING}

This research was supported by the NRF grant (NRF-2015R1A4A1041869) and C1 Gas Refinery Program through the National Research Foundation of Korea (NRF), which is funded

\section{REFERENCES}

Albertsen, M., Hugenholtz, P., Skarshewski, A., Nielsen, K. L., Tyson, G. W., and Nielsen, P. H. (2013). Genome sequences of rare, uncultured bacteria obtained by differential coverage binning of multiple metagenomes. Nat. Biotechnol. 31, 533-538. doi: 10.1038/nbt.2579

Amaral, J. A., Ren, T., and Knowles, R. (1998). Atmospheric methane consumption by forest soils and extracted bacteria at different $\mathrm{pH}$ values. Appl. Environ. Microbiol. 64, 2397-2402.

Andreas, K., Gaute, L., Hannah, H., Fuchs, B. M., Rudolf, A. I., and Kuypers, M. M. M. (2014). Distribution of a consortium between unicellular algae and the N2 fixing cyanobacterium UCYN-A in the North Atlantic Ocean. Environ. Microbiol. 16, 3153-3167. doi: 10.1111/1462-2920.12431

Arai, H., Hadi, A., Darung, U., Limin, S. H., Hatano, R., and Inubushi, K. (2014). A methanotrophic community in a tropical peatland is unaffected by drainage and forest fires in a tropical peat soil. Soil Sci. Plant Nutr. 60, 577-585. doi: 10.1080/00380768.2014.922034

Aronson, E. L., Allison, S. D., and Helliker, B. R. (2013). Environmental impacts on the diversity of methane-cycling microbes and their resultant function. Front. Microbiol. 4:225. doi: 10.3389/fmicb.2013.00225

Baesman, S. M., Miller, L. G., Wei, J. H., Cho, Y., Matys, E. D., Summons, R. E., et al. (2015). Methane oxidation and molecular characterization of methanotrophs from a former mercury mine impoundment. Microorganisms 3, 290-309. doi: 10.3390/microorganisms3020290

Baker-Austin, C., and Dopson, M. (2007). Life in acid: pH homeostasis in acidophiles. Trends Microbiol. 15, 165-171. doi: 10.1016/j.tim.2007.02.005

Baker-Austin, C., Dopson, M., Wexler, M., Sawers, R. G., and Bond, P. L. (2005). Molecular insight into extreme copper resistance in the extremophilic archaeon 'Ferroplasma acidarmanus' Fer1. Microbiology 151, 2637-2646. doi: 10.1099/ mic.0.28076-0

Bankevich, A., Nurk, S., Antipov, D., Gurevich, A. A., Dvorkin, M., Kulikov, A. S., et al. (2012). SPAdes: a new genome assembly algorithm and its applications to single-cell sequencing. J. Comput. Biol. 19, 455-477. doi: 10.1089/cmb.2012. 0021

Behera, S. K., and Shukla, A. K. (2015). Spatial distribution of durface doil acidity, electrical conductivity, soil organic carbon content and exchangeable potassium, calcium and magnesium in some cropped acid soils of India. Land Degrad. Dev. 26, 71-79. doi: 10.1002/ldr.2306

Belova, S. E., Kulichevskaya, I. S., Bodelier, P. L., and Dedysh, S. N. (2013). Methylocystis bryophila sp. nov., a facultatively methanotrophic bacterium from acidic Sphagnum peat, and emended description of the genus Methylocystis (ex Whittenbury et al. 1970) Bowman et al., 1993. Int. J. Syst. Evol. Microbiol. 63(Pt 3), 1096-1104. doi: 10.1099/ijs.0.043505-0

Bonamore, A., and Boffi, A. (2008). Flavohemoglobin: structure and reactivity. IUBMB Life 60, 19-28. doi: 10.1002/iub.9

Bowman, J. P., Sly, L. I., Nichols, P. D., and Hayward, A. C. (1993). Revised taxonomy of the methanotrophs: description of Methylobacter gen. nov., emendation of Methylococcus, validation of Methylosinus and Methylocystis species, and a proposal that the family Methylococcaceae includes only the group I methanotrophs. Int. J. Syst. Evol. Microbiol. 43, 735-753. doi: 10.1099/ 00207713-43-4-735

Buurman, E. T., Teixeira, de Mattos, M. J., and Neijssel, O. M. (1991). Futile cycling of ammonium ions via the high affinity potassium uptake system (Kdp) of Escherichia coli. Arch. Microbiol. 155, 391-395. doi: 10.1007/BF002 43460 by the Ministry of Science, ICT and Future Planning (NRF-2015M3D3A1A01064881).

\section{SUPPLEMENTARY MATERIAL}

The Supplementary Material for this article can be found online at: https://www.frontiersin.org/articles/10.3389/fmicb. 2018.01982/full\#supplementary-material

Cabello, P., Pino, C., Olmo-Mira, M. F., Castillo, F., Roldan, M. D., and MorenoVivian, C. (2004). Hydroxylamine assimilation by Rhodobacter capsulatus E1F1. requirement of the hcp gene (hybrid cluster protein) located in the nitrate assimilation nas gene region for hydroxylamine reduction. J. Biol. Chem. 279, 45485-45494. doi: 10.1074/jbc.M404417200

Caporaso, J. G., Kuczynski, J., Stombaugh, J., Bittinger, K., Bushman, F. D., Costello, E. K., et al. (2010). QIIME allows analysis of high-throughput community sequencing data. Nat. Methods 7, 335-336. doi: 10.1038/nmeth.f. 303

Castelle, C. J., Wrighton, K. C., Thomas, B. C., Hug, L. A., Brown, C. T., Wilkins, M. J., et al. (2015). Genomic expansion of domain archaea highlights roles for organisms from new phyla in anaerobic carbon cycling. Curr. Biol. 25, 690-701. doi: 10.1016/j.cub.2015.01.014

Cotter, P. D., and Hill, C. (2003). Surviving the acid test: responses of gram-positive bacteria to low pH. Microbiol. Mol. Biol. Rev. 67, 429-453. doi: 10.1128/MMBR. 67.3.429-453.2003

Dam, B., Dam, S., Blom, J., and Liesack, W. (2013). Genome analysis coupled with physiological studies reveals a diverse nitrogen metabolism in Methylocystis sp. strain SC2. PLoS One 8:e74767. doi: 10.1371/journal.pone.0074767

Danilova, O. V., Kulichevskaya, I. S., Rozova, O. N., Detkova, E. N., Bodelier, P. L., Trotsenko, Y. A., et al. (2013). Methylomonas paludis sp. nov., the first acidtolerant member of the genus Methylomonas, from an acidic wetland. Int. J. Syst. Evol. Microbiol. 63(Pt 6), 2282-2289. doi: 10.1099/ijs.0.045658-0

Dedysh, S. N. (2011). Cultivating uncultured bacteria from northern wetlands: knowledge gained and remaining gaps. Front. Microbiol. 2:184. doi: 10.3389/ fmicb.2011.00184

Dedysh, S. N., Belova, S. E., Bodelier, P. L., Smirnova, K. V., Khmelenina, V. N., Chidthaisong, A., et al. (2007). Methylocystis heyeri sp. nov., a novel type II methanotrophic bacterium possessing 'signature' fatty acids of type I methanotrophs. Int. J. Syst. Evol. Microbiol. 57(Pt 3), 472-479. doi: 10.1099/ijs. 0.64623-0

Dedysh, S. N., Berestovskaya, Y. Y., Vasylieva, L. V., Belova, S. E., Khmelenina, V. N., Suzina, N. E., et al. (2004). Methylocella tundrae sp. nov., a novel methanotrophic bacterium from acidic tundra peatlands. Int. J. Syst. Evol. Microbiol. 54(Pt 1), 151-156. doi: 10.1099/ijs.0.02805-0

Dedysh, S. N., Khmelenina, V. N., Suzina, N. E., Trotsenko, Y. A., Semrau, J. D., Liesack, W., et al. (2002). Methylocapsa acidiphila gen. nov., sp. nov., a novel methane-oxidizing and dinitrogen-fixing acidophilic bacterium from Sphagnum bog. Int. J. Syst. Evol. Microbiol. 52(Pt 1), 251-261. doi: 10.1099/ 00207713-52-1-251

Dedysh, S. N., Liesack, W., Khmelenina, V. N., Suzina, N. E., Trotsenko, Y. A., Semrau, J. D., et al. (2000). Methylocella palustris gen. nov., sp. nov., a new methane-oxidizing acidophilic bacterium from peat bogs, representing a novel subtype of serine-pathway methanotrophs. Int. J. Syst. Evol. Microbiol. 50(Pt 3), 955-969. doi: 10.1099/00207713-50-3-955

Dopson, M., and Holmes, D. S. (2014). Metal resistance in acidophilic microorganisms and its significance for biotechnologies. Appl. Microbiol. Biotechnol. 98, 8133-8144. doi: 10.1007/s00253-014-5982-2

Dunfield, P. F., Yuryev, A., Senin, P., Smirnova, A. V., Stott, M. B., Hou, S., et al. (2007). Methane oxidation by an extremely acidophilic bacterium of the phylum Verrucomicrobia. Nature 450, 879-882. doi: 10.1038/nature06411

Dutaur, L., and Verchot, L. V. (2007). A global inventory of the soil CH4 sink. Glob. Biogeochem. Cycles 21:GB4013, doi: 10.1029/2006GB002734

Esson, K. C., Lin, X., Kumaresan, D., Chanton, J. P., Murrell, J. C., and Kostka, J. E. (2016). Alpha- and gammaproteobacterial methanotrophs codominate 
the active methane-oxidizing communities in an acidic boreal peat bog. Appl. Environ. Microbiol. 82, 2363-2371. doi: 10.1128/AEM.03640-15

Ettwig, K. F., Butler, M. K., Le Paslier, D., Pelletier, E., Mangenot, S., Kuypers, M. M. M., et al. (2010). Nitrite-driven anaerobic methane oxidation by oxygenic bacteria. Nature 464:543. doi: 10.1038/nature08883

Felsenstein, J. (1985). Confidence limits on phylogenies: an approach using the bootstrap. Evolution 39, 783-791. doi: 10.1111/j.1558-5646.1985.tb00420.x

Forgac, M. (2007). Vacuolar ATPases: rotary proton pumps in physiology and pathophysiology. Nat. Rev. Mol. Cell Biol. 8, 917-929. doi: 10.1038/nrm2272

Foster, J. W. (2004). Escherichia coli acid resistance: tales of an amateur acidophile. Nat. Rev. Microbiol. 2, 898-907. doi: 10.1038/nrmicro1021

Fuse, H., Ohta, M., Takimura, O., Murakami, K., Inoue, H., Yamaoka, Y., et al. (1998). Oxidation of trichloroethylene and dimethyl sulfide by a marine Methylomicrobium strain containing soluble methane monooxygenase. Biosci. Biotechnol. Biochem. 62, 1925-1931. doi: 10.1271/bbb.62.1925

Gajiwala, K. S., and Burley, S. K. (2000). HDEA, a periplasmic protein that supports acid resistance in pathogenic enteric bacteria. J. Mol. Biol. 295, 605-612. doi: 10.1006/jmbi.1999.3347

Goulding, K. W. (2016). Soil acidification and the importance of liming agricultural soils with particular reference to the United Kingdom. Soil Use Manage. 32, 390-399. doi: 10.1111/sum.12270

Griffiths, R. I., Whiteley, A. S., O'Donnell, A. G., and Bailey, M. J. (2000). Rapid method for coextraction of DNA and RNA from natural environments for analysis of ribosomal DNA- and rRNA-based microbial community composition. Appl. Environ. Microbiol. 66, 5488-5491. doi: 10.1128/AEM.66. 12.5488-5491.2000

Grissa, I., Vergnaud, G., and Pourcel, C. (2007). CRISPRFinder: a web tool to identify clustered regularly interspaced short palindromic repeats. Nucleic Acids Res. 35, W52-W57. doi: 10.1093/nar/gkm360

Haft, D. H., Loftus, B. J., Richardson, D. L., Yang, F., Eisen, J. A., Paulsen, I. T., et al. (2001). TIGRFAMs: a protein family resource for the functional identification of proteins. Nucleic Acids Res. 29, 41-43. doi: 10.1093/nar/29.1.41

Hall, T. A. (1999). BioEdit: a user-friendly biological sequence alignment editor and analysis program for Windows 95/98/NT. Nucl. Acids. Symp. Ser. 41, 95-98.

Hamilton, R., Kits, K. D., Ramonovskaya, V. A., Rozova, O. N., Yurimoto, H., Iguchi, H., et al. (2015). Draft genomes of gammaproteobacterial methanotrophs isolated from terrestrial ecosystems. Genome Announc 3:e515. doi: 10.1128/genomeA.00515-15

Hanson, R. S., and Hanson, T. E. (1996). Methanotrophic bacteria. Microbiol. Rev. $60,439-471$.

He, Z., Cai, C., Wang, J., Xu, X., Zheng, P., Jetten, M. S., et al. (2016). A novel denitrifying methanotroph of the NC10 phylum and its microcolony. Sci. Rep. 6:32241. doi: $10.1038 / \mathrm{srep} 32241$

Herz, K., Vimont, S., Padan, E., and Berche, P. (2003). Roles of NhaA, NhaB, and $\mathrm{NhaD} \mathrm{Na}+/ \mathrm{H}+$ antiporters in survival of Vibrio cholerae in a saline environment. J. Bacteriol. 185, 1236-1244. doi: 10.1128/JB.185.4.1236-1244. 2003

Hofmann, K., Praeg, N., Mutschlechner, M., Wagner, A. O., and Illmer, P. (2016). Abundance and potential metabolic activity of methanogens in well-aerated forest and grassland soils of an alpine region. FEMS Microbiol. Ecol. 92:fiv171. doi: $10.1093 /$ femsec/fiv171

Hou, S., Makarova, K. S., Saw, J. H., Senin, P., Ly, B. V., Zhou, Z., et al. (2008). Complete genome sequence of the extremely acidophilic methanotroph isolate V4, Methylacidiphilum infernorum, a representative of the bacterial phylum Verrucomicrobia. Biol. Direct 3:26. doi: 10.1186/17456150-3-26

Hyatt, D., Chen, G. L., Locascio, P. F., Land, M. L., Larimer, F. W., and Hauser, L. J. (2010). Prodigal: prokaryotic gene recognition and translation initiation site identification. BMC Bioinformatics 11:119. doi: 10.1186/1471-2105-11-119

Iguchi, H., Yurimoto, H., and Sakai, Y. (2011). Stimulation of methanotrophic growth in cocultures by cobalamin excreted by rhizobia. Appl. Environ. Microbiol. 77, 8509-8515. doi: 10.1128/aem.05834-11

Islam, T., Torsvik, V., Larsen, O., Bodrossy, L., Ovreas, L., and Birkeland, N. K. (2016). Acid-tolerant moderately thermophilic methanotrophs of the class gammaproteobacteria isolated from tropical topsoil with methane seeps. Front. Microbiol. 7:851. doi: 10.3389/fmicb.2016.00851

Johnson, D. B. (1998). Biodiversity and ecology of acidophilic microorganisms. FEMS Microbiol. Ecol. 27, 307-317. doi: 10.1111/j.1574-6941.1998.tb00547.x
Jones, D. S., Albrecht, H. L., Dawson, K. S., Schaperdoth, I., Freeman, K. H., $\mathrm{Pi}$, Y., et al. (2012). Community genomic analysis of an extremely acidophilic sulfur-oxidizing biofilm. ISME J. 6, 158-170. doi: 10.1038/ismej.2011.75

Joshi, N. A., and Fass, J. N. (2011). Sickle: A Sliding-Window, Adaptive, QualityBased Trimming Tool for FastQ Files (Version 1.33). Available at: https://github. com/najoshi/sickle

Kanehisa, M., Furumichi, M., Tanabe, M., Sato, Y., and Morishima, K. (2017). KEGG: new perspectives on genomes, pathways, diseases and drugs. Nucleic Acids Res. 45, D353-D361. doi: 10.1093/nar/gkw1092

Kelly, D. P., Anthony, C., and Murrell, J. C. (2005). Insights into the obligate methanotroph Methylococcus capsulatus. Trends Microbiol. 13, 195-198. doi: 10.1016/j.tim.2005.03.003

Kim, J., Kim, D. D., and Yoon, S. (2018). Rapid isolation of fast-growing methanotrophs from environmental samples using continuous cultivation with gradually increased dilution rates. Appl. Microbiol. Biotechnol. 102, 5707-5715. doi: 10.1007/s00253-018-8978-5

Kip, N., Ouyang, W., van Winden, J., Raghoebarsing, A., van Niftrik, L., Pol, A., et al. (2011). Detection, isolation, and characterization of acidophilic methanotrophs from Sphagnum mosses. Appl. Environ. Microbiol. 77, 56435654. doi: 10.1128/AEM.05017-11

Kizilova, A., Yurkov, A., and Kravchenko, I. (2013). Aerobic methanotrophs in natural and agricultural soils of European Russia. Diversity 5, 541-556. doi: $10.3390 / \mathrm{d} 5030541$

Knief, C. (2015). Diversity and habitat preferences of cultivated and uncultivated aerobic methanotrophic bacteria evaluated based on pmoA as molecular marker. Front. Microbiol. 6:1346. doi: 10.3389/fmicb.2015.01346

Kolb, S., Knief, C., Dunfield, P. F., and Conrad, R. (2005). Abundance and activity of uncultured methanotrophic bacteria involved in the consumption of atmospheric methane in two forest soils. Environ. Microbiol. 7, 1150-1161. doi: 10.1111/j.1462-2920.2005.00791.x

Kolb, S., Knief, C., Stubner, S., and Conrad, R. (2003). Quantitative detection of methanotrophs in soil by novel pmoA-targeted real-time PCR assays. Appl. Environ. Microbiol. 69, 2423-2429. doi: 10.1128/AEM.69.5.2423-2429.2003

Krause, S. M. B., Johnson, T., Samadhi Karunaratne, Y., Fu, Y., Beck, D. A. C., Chistoserdova, L., et al. (2017). Lanthanide-dependent cross-feeding of methane-derived carbon is linked by microbial community interactions. Proc. Natl. Acad. Sci. U.S.A. 114, 358-363. doi: 10.1073/pnas.1619871114

Kumar, S., Stecher, G., and Tamura, K. (2016). MEGA7: molecular evolutionary genetics analysis version 7.0 for bigger datasets. Mol. Biol. Evol. 33, 1870-1874. doi: 10.1093/molbev/msw054

Lagesen, K., Hallin, P., Rodland, E. A., Staerfeldt, H. H., Rognes, T., and Ussery, D. W. (2007). RNAmmer: consistent and rapid annotation of ribosomal RNA genes. Nucleic Acids Res. 35, 3100-3108. doi: 10.1093/nar/gkm160

Langmead, B., and Salzberg, S. L. (2012). Fast gapped-read alignment with Bowtie 2. Nat. Methods 9, 357-359. doi: 10.1038/nmeth.1923

Lau, E., Ahmad, A., Steudler, P. A., and Cavanaugh, C. M. (2007). Molecular characterization of methanotrophic communities in forest soils that consume atmospheric methane. FEMS Microbiol. Ecol. 60, 490-500. doi: 10.1111/j.15746941.2007.00308.x

Le Mer, J., and Roger, P. (2001). Production, oxidation, emission and consumption of methane by soils: a review. Eur. J. Soil Biol. 37, 25-50. doi: 10.1016/S11645563(01)01067-6

Lee, I., Kim, Y. O., Park, S. C., and Chun, J. (2015). OrthoANI: An improved algorithm and software for calculating average nucleotide identity. Int. J. Syst. Evol. Microbiol. 66, 1100-1103. doi: 10.1099/ijsem.0.000760

Leone, V., Pogoryelov, D., Meier, T., and Faraldo-Gomez, J. D. (2015). On the principle of ion selectivity in $\mathrm{Na}+/ \mathrm{H}+$-coupled membrane proteins: experimental and theoretical studies of an ATP synthase rotor. Proc. Natl. Acad. Sci. U.S.A. 112, E1057-E1066. doi: 10.1073/pnas.1421202112

Li, H., Handsaker, B., Wysoker, A., Fennell, T., Ruan, J., Homer, N., et al. (2009). The sequence alignment/Map format and SAMtools. Bioinformatics 25, 20782079. doi: 10.1093/bioinformatics/btp352

Lolkema, J. S., Chaban, Y., and Boekema, E. J. (2003). Subunit composition, structure, and distribution of bacterial V-type ATPases. J. Bioenerg. Biomembr. 35, 323-335. doi: 10.1023/A:1025776831494

Lowe, T. M., and Chan, P. P. (2016). tRNAscan-SE On-line: integrating search and context for analysis of transfer RNA genes. Nucleic Acids Res. 44, W54-W57. doi: 10.1093/nar/gkw413 
Lund, P., Tramonti, A., and De Biase, D. (2014). Coping with low pH: molecular strategies in neutralophilic bacteria. FEMS Microbiol. Rev. 38, 1091-1125. doi: 10.1111/1574-6976.12076

Machacova, K., Bäck, J., Vanhatalo, A., Halmeenmäki, E., Kolari, P., Mammarella, I., et al. (2016). Pinus sylvestris as a missing source of nitrous oxide and methane in boreal forest. Sci. Rep. 6:23410. doi: 10.1038/srep23410

Makarova, K. S., Haft, D. H., Barrangou, R., Brouns, S. J., Charpentier, E., Horvath, P., et al. (2011). Evolution and classification of the CRISPR-Cas systems. Nat. Rev. Microbiol. 9, 467-477. doi: 10.1038/nrmicro2577

Mangold, S., Potrykus, J., Bjorn, E., Lovgren, L., and Dopson, M. (2013a). Extreme zinc tolerance in acidophilic microorganisms from the bacterial and archaeal domains. Extremophiles 17, 75-85. doi: 10.1007/s00792-012-0495-3

Mangold, S., Rao Jonna, V., and Dopson, M. (2013b). Response of Acidithiobacillus caldus toward suboptimal pH conditions. Extremophiles 17, 689-696. doi: 10. 1007/s00792-013-0553-5

Megonigal, J. P., and Guenther, A. B. (2008). Methane emissions from upland forest soils and vegetation. Tree Physiol. 28, 491-498. doi: 10.1093/treephys/28.4.491

Merrell, D. S., and Camilli, A. (2002). Acid tolerance of gastrointestinal pathogens. Curr. Opin. Microbiol. 5, 51-55. doi: 10.1016/S1369-5274(02) 00285-0

Mogk, A., Deuerling, E., Vorderwulbecke, S., Vierling, E., and Bukau, B. (2003). Small heat shock proteins, ClpB and the DnaK system form a functional triade in reversing protein aggregation. Mol. Microbiol. 50, 585-595. doi: 10.1046/j. 1365-2958.2003.03710.x

Muhling, M., Poehlein, A., Stuhr, A., Voitel, M., Daniel, R., and Schlomann, M. (2016). Reconstruction of the metabolic potential of acidophilic sideroxydans strains from the metagenome of an microaerophilic enrichment culture of acidophilic iron-oxidizing bacteria from a pilot plant for the treatment of acid mine drainage reveals metabolic versatility and adaptation to life at low $\mathrm{pH}$. Front. Microbiol. 7:2082. doi: 10.3389/fmicb.2016.02082

Mukhin, V. A., and Voronin, P. Y. (2011). Methane emission from living tree wood. Russ. J. Plant Physiol. 58, 344-350. doi: 10.1134/s1021443711020117

Murata, T., Yamato, I., Kakinuma, Y., Shirouzu, M., Walker, J. E., Yokoyama, S., et al. (2008). Ion binding and selectivity of the rotor ring of the $\mathrm{Na}+$ transporting V-ATPase. Proc. Natl. Acad. Sci. U.S.A. 105, 8607-8612. doi: 10. 1073/pnas.0800992105

Muyzer, G., de Waal, E. C., and Uitterlinden, A. G. (1993). Profiling of complex microbial populations by denaturing gradient gel electrophoresis analysis of polymerase chain reaction-amplified genes coding for $16 \mathrm{~S}$ rRNA. Appl. Environ. Microbiol. 59, 695-700.

Nordstrom, D. K., and Alpers, C. N. (1999). Negative pH, efflorescent mineralogy, and consequences for environmental restoration at the Iron Mountain Superfund site, California. Proc. Natl. Acad. Sci. U.S.A. 96, 3455-3462. doi: 10.1073/pnas.96.7.3455

Nordstrom, D. K., Alpers, C. N., Ptacek, C. J., and Blowes, D. W. (2000). Negative $\mathrm{pH}$ and extremely acidic mine waters from Iron Mountain, California. Environ. Sci. Technol. 34, 254-258. doi: 10.1021/es990646v

Osburn, M. R., Sessions, A. L., Pepe-Ranney, C., and Spear, J. R. (2011). Hydrogenisotopic variability in fatty acids from Yellowstone National Park hot spring microbial communities. Geochim. Cosmochim. Acta 75, 4830-4845. doi: 10. 1016/j.gca.2011.05.038

Oshkin, I. Y., Beck, D. A., Lamb, A. E., Tchesnokova, V., Benuska, G., McTaggart, T. L., et al. (2015). Methane-fed microbial microcosms show differential community dynamics and pinpoint taxa involved in communal response. ISME J. 9, 1119-1129. doi: 10.1038/ismej.2014.203

Oshkin, I. Y., Belova, S. E., Danilova, O. V., Miroshnikov, K. K., Rijpstra, W. I., Sinninghe Damste, J. S., et al. (2016). Methylovulum psychrotolerans sp. nov., a cold-adapted methanotroph from low-temperature terrestrial environments, and emended description of the genus Methylovulum. Int. J. Syst. Evol. Microbiol. 66, 2417-2423. doi: 10.1099/ijsem.0.001046

Parks, D. H., Imelfort, M., Skennerton, C. T., Hugenholtz, P., and Tyson, G. W. (2015). CheckM: assessing the quality of microbial genomes recovered from isolates, single cells, and metagenomes. Genome Res. 25, 1043-1055. doi: 10. 1101/gr.186072.114

Peng, T., Ma, L., Feng, X., Tao, J., Nan, M., Liu, Y., et al. (2017). Genomic and transcriptomic analyses reveal adaptation mechanisms of an Acidithiobacillus ferrivorans strain YL15 to alpine acid mine drainage. PLoS One 12:e0178008. doi: 10.1371/journal.pone.0178008
Phanstiel, D. H., Boyle, A. P., Araya, C. L., and Snyder, M. P. (2014). Sushi.R: flexible, quantitative and integrative genomic visualizations for publicationquality multi-panel figures. Bioinformatics 30, 2808-2810. doi: 10.1093/ bioinformatics/btu379

Quatrini, R., Ossandon, F. J., and Rawlings, D. (2016). "The flexible genome of acidophilic prokaryotes," in Life in Extremely Acidic Environments, eds R. Quatrini and D. B. Johnson (Norfolk, VA: Caister Academic Press), 199-220. doi: 10.21775/9781910190333.12

Raghoebarsing, A. A., Pol, A., van de Pas-Schoonen, K. T., Smolders, A. J., Ettwig, K. F., Rijpstra, W. I., et al. (2006). A microbial consortium couples anaerobic methane oxidation to denitrification. Nature 440, 918-921. doi: 10. 1038/nature04617

Rath, D., Amlinger, L., Rath, A., and Lundgren, M. (2015). The CRISPR-Cas immune system: biology, mechanisms and applications. Biochimie 117, 119128. doi: 10.1016/j.biochi.2015.03.025

Rossello-Mora, R., and Amann, R. (2015). Past and future species definitions for bacteria and archaea. Syst. Appl. Microbiol. 38, 209-216. doi: 10.1016/j.syapm. 2015.02.001

Saari, A., Rinnan, R., and Martikainen, P. J. (2004). Methane oxidation in boreal forest soils: kinetics and sensitivity to $\mathrm{pH}$ and ammonium. Soil Biol. Biochem. 36, 1037-1046. doi: 10.1016/j.soilbio.2004.01.018

Saitou, N., and Nei, M. (1987). The neighbor-joining method: a new method for reconstructing phylogenetic trees. Mol. Biol. Evol. 4, 406-425.

Samai, P., Pyenson, N., Jiang, W., Goldberg, G. W., Hatoum-Aslan, A., and Marraffini, L. A. (2015). Co-transcriptional DNA and RNA cleavage during type III CRISPR-cas immunity. Cell 161, 1164-1174. doi: 10.1016/j.cell.2015. 04.027

Schlegel, K., Leone, V., Faraldo-Gomez, J. D., and Muller, V. (2012). Promiscuous archaeal ATP synthase concurrently coupled to $\mathrm{Na}+$ and $\mathrm{H}+$ translocation. Proc. Natl. Acad. Sci. U.S.A. 109, 947-952. doi: 10.1073/pnas.1115796109

Scott, D. R., Marcus, E. A., Wen, Y., Singh, S., Feng, J., and Sachs, G. (2010). Cytoplasmic histidine kinase (HP0244)-regulated assembly of urease with UreI, a channel for urea and its metabolites, CO2, NH3, and $\mathrm{NH} 4+$, is necessary for acid survival of Helicobacter pylori. J. Bacteriol. 192, 94-103. doi: 10.1128/JB. 00848-09

Semrau, J. D. (2011). Bioremediation via methanotrophy: overview of recent findings and suggestions for future research. Front. Microbiol. 2:209. doi: 10. 3389/fmicb.2011.00209

Sharp, C. E., Smirnova, A. V., Graham, J. M., Stott, M. B., Khadka, R., Moore, T. R., et al. (2014). Distribution and diversity of Verrucomicrobia methanotrophs in geothermal and acidic environments. Environ. Microbiol. 16, 1867-1878. doi: 10.1111/1462-2920.12454

Silver, S., and Phung, L. T. (1996). Bacterial heavy metal resistance: new surprises. Annu. Rev. Microbiol. 50, 753-789. doi: 10.1146/annurev.micro.50.1.753

Singh, S. K., Singh, A., and Banerjee, P. C. (2010). Plasmid encoded AcrABTolC tripartite multidrug-efflux system in Acidiphilium symbioticum H8. Curr. Microbiol. 61, 163-168. doi: 10.1007/s00284-010-9590-9

Söhngen, N. L. (1906). Ueber bakterien, welche methan als kohlenstoffnahrung und energiequelle gebrauchen. Centralbl. Bakt. II 15, 513-517.

Sorek, R., Zhu, Y., Creevey, C. J., Francino, M. P., Bork, P., and Rubin, E. M. (2007). Genome-wide experimental determination of barriers to horizontal gene transfer. Science 318, 1449-1452. doi: 10.1126/science.1147112

Stingl, K., Altendorf, K., and Bakker, E. P. (2002). Acid survival of Helicobacter pylori: how does urease activity trigger cytoplasmic $\mathrm{pH}$ homeostasis? Trends Microbiol. 10, 70-74. doi: 10.1016/S0966-842X(01)02287-9

Strong, P. J., Xie, S., and Clarke, W. P. (2015). Methane as a resource: can the methanotrophs add value? Environ. Sci. Technol. 49, 4001-4018. doi: 10.1021/ es504242n

Sugimoto, S., Yoshida, H., Mizunoe, Y., Tsuruno, K., Nakayama, J., and Sonomoto, K. (2006). Structural and functional conversion of molecular chaperone $\mathrm{ClpB}$ from the gram-positive halophilic lactic acid bacterium Tetragenococcus halophilus mediated by ATP and stress. J. Bacteriol. 188, 8070-8078. doi: 10.1128/JB.00404-06

Tamas, I., Smirnova, A. V., He, Z., and Dunfield, P. F. (2014). The (d)evolution of methanotrophy in the beijerinckiaceae - A comparative genomics analysis. ISME J. 8, 369-382. doi: 10.1038/ismej.2013.145

Tatusov, R. L., Natale, D. A., Garkavtsev, I. V., Tatusova, T. A., Shankavaram, U. T., Rao, B. S., et al. (2001). The COG database: new developments in phylogenetic 
classification of proteins from complete genomes. Nucleic Acids Res. 29, 22-28. doi: 10.1093/nar/29.1.22

Tavormina, P. L., Orphan, V. J., Kalyuzhnaya, M. G., Jetten, M. S., and Klotz, M. G. (2011). A novel family of functional operons encoding methane/ammonia monooxygenase-related proteins in gammaproteobacterial methanotrophs. Environ. Microbiol. Rep. 3, 91-100. doi: 10.1111/j.1758-2229.2010.00192.x

Thompson, C. C., Amaral, G. R., Campeao, M., Edwards, R. A., Polz, M. F., Dutilh, B. E., et al. (2015). Microbial taxonomy in the post-genomic era: rebuilding from scratch? Arch. Microbiol. 197, 359-370. doi: 10.1007/s00203-014-1071-2

Thompson, J. D., Gibson, T. J., Plewniak, F., Jeanmougin, F., and Higgins, D. G. (1997). The CLUSTAL_X windows interface: flexible strategies for multiple sequence alignment aided by quality analysis tools. Nucleic Acids Res. 25, 4876-4882. doi: 10.1093/nar/25.24.4876

Tindall, B. J., Rossello-Mora, R., Busse, H. J., Ludwig, W., and Kampfer, P. (2010). Notes on the characterization of prokaryote strains for taxonomic purposes. Int J. Syst. Evol. Microbiol. 60(Pt 1), 249-266. doi: 10.1099/ijs.0.016949-0

Tucker, D. L., Tucker, N., and Conway, T. (2002). Gene expression profiling of the $\mathrm{pH}$ response in Escherichia coli. J. Bacteriol. 184, 6551-6558. doi: 10.1128/JB. 184.23.6551-6558.2002

Vekeman, B., Speth, D., Wille, J., Cremers, G., De Vos, P., Op, et al. (2016). Genome characteristics of two novel type I methanotrophs enriched from north sea sediments containing exclusively a lanthanide-dependent XoxF5-type methanol dehydrogenase. Microb. Ecol. 72, 503-509. doi: 10.1007/s00248-0160808-7

Villesen, P. (2007). FaBox: an online toolbox for fasta sequences. Mol. Ecol. Notes 7, 965-968. doi: 10.1111/j.1471-8286.2007.01821.x

Vorobev, A., Jagadevan, S., Jain, S., Anantharaman, K., Dick, G. J., Vuilleumier, S., et al. (2014). Genomic and transcriptomic analyses of the facultative methanotroph Methylocystis sp. strain SB2 grown on methane or ethanol. Appl. Environ. Microbiol. 80, 3044-3052. doi: 10.1128/AEM. 00218-14

Vorobev, A. V., Baani, M., Doronina, N. V., Brady, A. L., Liesack, W., Dunfield, P. F., et al. (2011). Methyloferula stellata gen. nov., sp. nov., an acidophilic, obligately methanotrophic bacterium that possesses only a soluble methane monooxygenase. Int. J. Syst. Evol. Microbiol. 61(Pt 10), 2456-2463. doi: 10.1099/ ijs.0.028118-0

Wang, Y., Coleman-Derr, D., Chen, G., and Gu, Y. Q. (2015). OrthoVenn: a web server for genome wide comparison and annotation of orthologous clusters across multiple species. Nucleic Acids Res. 43, W78-W84. doi: 10.1093/nar/ gkv487

Wartiainen, I., Hestnes, A. G., McDonald, I. R., and Svenning, M. M. (2006). Methylobacter tundripaludum sp. nov., a methane-oxidizing bacterium from Arctic wetland soil on the Svalbard islands, Norway (78 degrees N). Int. J. Syst. Evol. Microbiol. 56(Pt 1), 109-113. doi: 10.1099/ijs.0.63728-0

Widdel, F., and Bak, F. (1992). "'Gram-negative mesophilic sulfate-reducing bacteria," in The Prokaryotes: A Handbook on the Biology of Bacteria: Ecophysiology, Isolation, Identification, Applications, eds A. Balows, H. G. Trüper, M. Dworkin, W. Harder, and K.-H. Schleifer (New York, NY: Springer), 3352-3378.

Wolfe, M. T., Heo, J., Garavelli, J. S., and Ludden, P. W. (2002). Hydroxylamine reductase activity of the hybrid cluster protein from Escherichia coli. J. Bacteriol. 184, 5898-5902. doi: 10.1128/JB.184.21.5898-5902.2002

Yoon, S. H., Ha, S. M., Kwon, S., Lim, J., Kim, Y., Seo, H., et al. (2017). Introducing EzBioCloud: a taxonomically united database of $16 \mathrm{~S}$ rRNA gene sequences and whole-genome assemblies. Int. J. Syst. Evol. Microbiol. 67, 1613-1617. doi: 10.1099/ijsem.0.001755

Yu, L., Wang, Y., Wang, Y., Sun, S., and Liu, L. (2015). Quantifying components of soil respiration and their response to abiotic factors in two typical subtropical forest stands, southwest China. PLoS One 10:e0117490. doi: 10.1371/journal. pone. 0117490

Zhou, X., Guo, Z., Chen, C., and Jia, Z. (2017). Soil microbial community structure and diversity are largely influenced by soil $\mathrm{pH}$ and nutrient quality in 78-yearold tree plantations. Biogeosciences 14, 2101-2111. doi: 10.5194/bg-14-21012017

Conflict of Interest Statement: The authors declare that the research was conducted in the absence of any commercial or financial relationships that could be construed as a potential conflict of interest.

Copyright (c) 2018 Nguyen, Yu, Gwak, Kim, Park, Herbold, Kim, Jung and Rhee. This is an open-access article distributed under the terms of the Creative Commons Attribution License (CC BY). The use, distribution or reproduction in other forums is permitted, provided the original author(s) and the copyright owner(s) are credited and that the original publication in this journal is cited, in accordance with accepted academic practice. No use, distribution or reproduction is permitted which does not comply with these terms. 